\title{
Solid State Physicochemical Properties and Applications of Organic and Metallo-Organic Fullerene Derivatives
}

\author{
Efstratia Mitsari, Michela Romanini, Manesh Zachariah, and Roberto Macovez ${ }^{*}$ \\ Grup de Caracterització de Materials, Universitat Politècnica de Catalunya (UPC). ETSEIB, Departament de Fisica i \\ Enginyeria Nuclear, Av. Diagonal 647, E-08028 Barcelona, Spain
}

\begin{abstract}
We review the fundamental properties and main applications of organic derivatives and complexes of fullerenes in the solid-state form. We address in particular the structural properties, in terms of crystal structure, polymorphism, orientational transitions and morphology, and the electronic structure and derived properties, such as chemical activity, electrical conduction mechanisms, optical properties, heat conduction and magnetism. The last two sections of the review focus on the solid-state optoelectronic and electrochemical applications of fullerene derivatives, which range from photovoltaic cells to field-effect transistors and photodetectors on one hand, to electron-beam resists, electrolytes and energy storage on the other.
\end{abstract}

Keywords: Crystal structure; Electrical conduction; Electrochemistry; Fullerene; Molecular complexes; Optoelectronic properties; Organic functionalization.

\section{INTRODUCTION}

Fullerenes, which represent the fourth known allotrope of carbon after diamond, graphite and amorphous carbon, were considered for some time promising materials for a wide range of applications. However, the utilization of these remarkable all-carbon molecules for applications in biochemistry and medicine or low-cost device fabrication is hindered by their insolubility in a large number of solvents (besides organic ones [1]) including especially water, where clustering of the molecules is reported [2], and by their low stability under ambient conditions in powder and thin-film form $[3,4]$. Fullerene derivatization aims on one hand at overcoming these shortcomings of the parent moieties, and on the other hand to confer the all-carbon cages enhanced physicochemical functionalities.

We describe here the basic solid-state properties of fullerene derivatives, focusing especially on the functionalization of the lowest-molecular mass fullerene, the buckyball or buckminsterfullerene $\mathrm{C}_{60}$. In some cases a comparison with pristine fullerite (solid $\mathrm{C}_{60}$ ) or with simple inorganic salts of $\mathrm{C}_{60}$ (e.g., alkali fullerides) will be made in order to highlight the effect of functionalization. The basic solid-state property is the structural arrangements of the molecules, which include the position of their centers of mass as well as their orientation and possible distortions from the quasi-spherical shape. For a globular molecule like fullerene, the most important degrees of freedom in the condensed state are conformational and orientational (rotational) ones.

*Address correspondence to this author at ETSEIB - Universitat Politècnica de Catalunya (UPC), Av. Diagonal 647, E-08028 Barcelona, Spain; Tel: +349340 16568; E-mail: roberto.macovez@upc.edu
For example, fullerite displays at room temperature a socalled "rotator" phase (also referred to as "plastic crystal" phase), in which the molecules spin around their centers of mass as free rotors. As the temperature is lowered, two solidsolid transitions are observed, both of which arise from the rotational degrees of freedom.

As in most molecular solids, the vibrational states in fullerite (apart from librations) are in general only weakly affected by intermolecular interactions, and are better described as quasiintramolecular vibrations than as intermolecular phonon modes as in inorganic crystals. The same holds for the electronic band structure, which is composed of narrow bands directly derived from corresponding molecular orbitals. Under these circumstances, it is the intermolecular coupling to nearest-neighbor molecules (rather than the delocalized interactions as in conventional solids) that is responsible for macroscopic properties such as charge and heat transport, structural and magnetic ordering, and of optical properties such as the lifetime of excitonic states. Functionalization or complex formation with other organic moieties modifies the electronic levels and vibrational modes of the individual fullerene molecules, and thus the derived electronic bands and phonon states in the solid state, which as discussed mainly reflect those of isolated fullerene derivatives; but it also leads to a different intermolecular coupling, which may affect charge conduction or magnetic properties.

As most organic molecular materials, fullerenes and their derivatives are semiconducting or insulating in the solid state. $\mathrm{C}_{60}$ is an electron-accepting molecule [5,6], and this property is retained by most of its derivatives [7]. These fundamental properties of fullerenes make them very attractive semiconducting systems for charge-separation and electron-transport devices, such as light detectors, $n$-channel field-effect transistors, or solar cells. While devices based on 
$\mathrm{C}_{60}$ have been mostly obtained using high-vacuum filmdeposition techniques and are destroyed if exposed to air, chemical functionalization yields derivatives that are soluble in a wider range of solvents and less prone to photooxidation (see Section A). These derivatives can therefore be solutionprocessed to obtain air-stable films for e.g. (opto)electronics and electrochemistry applications.

We start by reviewing the molecular structure of fullerene derivatives and the general goals of functionalization (Section A), to then move on to the study of the solid-state structural properties and phase behavior of functionalized fullerenes (including magnetic transitions, Section B) and to their electronic and optical properties (Section C). We conclude with a discussion of the implementation of fullerene derivatives in electronic and optoelectronic devices, such as field-effect transistors, bulk heterojunction solar cells or light detectors (Section D), and in solid-state chemistry applications such as surface catalysis, electrochemical devices or chemically amplified electron-beam lithography (Section E).

\section{A) OVERVIEW OF FULLERENE DERIVATIVES}

The discovery of buckminsterfullerene $\left(\mathrm{C}_{60}\right)$ in 1985 [8] and five years later of a protocol for its bulk production [9] triggered an intense research activity on pristine fullerenes in the last decade of the past century. More recently, the limits of practical applications of unfunctionalized fullerenes have began to emerge (e.g. due to instability in film-form or poor processability) and the focus of the community of researchers working on carbon-based materials has shifted towards other carbon structures such as nanotubes or graphene. While pristine fullerenes have become standard model systems which are still very widely used in fundamental physical studies, the focus of applied fullerene research has shifted to fullerene derivatives. As will be shown in the following, in recent years a number of important studies have appeared on solid-state applications of functionalized fullerenes. Buckminsterfullerene is usually the preferred substrate for functionalization, as its higher molecular symmetry compared to the other fullerenes leads to a lower number of possible isomers in the functionalization products. Also because the derivatives of $\mathrm{C}_{60}$ are the most studied ones, most of the review will focus on these systems.

\section{A.1. General aims of the organic functionalization of fullerene}

Organic derivatization of the all-carbon fullerene molecules is carried out to obtain new molecules with enhanced/modified properties or functions. The targeted functionalities cover a wide spectrum of physico-chemical properties, summarized in what follows.

i) Enhanced device stability in air. Pristine $\mathrm{C}_{60}$ in powder and thin-film form is unstable under ambient conditions. In fact, due to the relatively large (on the atomic scale) interstitial voids between the molecules in pristine fullerite, molecular oxygen readily diffuses into it [10]. Subsequent illumination by light triggers photochemical reactions leading to $\mathrm{C}-\mathrm{O}$ binding and disruption of the fullerene cages.[3,4] For this reason, $\mathrm{C}_{60}$ is normally stored under noillumination conditions, and $\mathrm{C}_{60}$ films and devices are only achieved and characterized under vacuum or inert atmosphere, often requiring in situ measurements on freshly deposited samples. Fullerene functionalization can prevent photo-oxidation, either by changing the chemical reactivity of charged fullerene moieties by modifying the energy position of the lowest unoccupied molecular orbital (LUMO) with respect to the trap energy of adsorbed atmospheric oxidants (oxygen and water), or by introducing sideadducts that modify the solid-state structure and act as a barrier against oxygen or water diffusion $[11,12]$.

ii) Tuneable hydrophilic character and solubility in water. $\mathrm{C}_{60}$ and higher fullerenes are hydrophobic and exhibit very poor solubility in water. The mechanism of fullerite solvation in water involves the surface hydroxylation of fullerene clusters, that is to say, a sort of spontaneous derivatization: $\mathrm{C}_{60}$ crystals are split by interaction with the $\mathrm{H}_{2} \mathrm{O}$ molecules into $\mathrm{C}_{60}$ clusters whose outer surface becomes functionalized with $\mathrm{OH}$ groups [13]. Similarly, enhanced water solubility can be achieved through synthetic methods by addition of hydrophilic sidegroups (hydroxyl, amine, etc.) to the carbon cage. Although at least partial solubility in aqueous solvents is ensured when a hydrophilic appendage is covalently attached to $C_{60}$ [14], addition of only one solubilizing chain is usually insufficient to avoid clustering of the derivatives. The hydrophobic carbon spheres tend in such case to stick together, leaving the hydrophilic chains on the outside of the aggregate $[15,16]$. One of the highest water solubilities for monofunctionalized fullerenes is attributed to a double-headed dendrimer structure covalently linked by an epoxy bridge to a $\mathrm{C}_{60}$ molecule [17]. In this case, the size of the sideadduct is comparable with that of the carbon cage itself. In a similar manner, water soluble polymers usually retain their solubility also when they are covalently linked to fullerene species [18].

A large number of water-soluble fullerene derivatives have been synthesized.[14] Polyhydroxilated fullerene (also known as fullerenol or fullerol, of chemical formula $\mathrm{C}_{60}(\mathrm{OH})_{n}$ with $n$ between 6 and 44), one of the most studied fullerene derivatives, shows increasing solubility with increasing number of side-adducts. Generally, a fullerenol with fewer than 12 hydroxyl groups on the fullerene cage shows only slight water solubility $[19,20,21]$, whereas the fullerenols with a higher number of hydroxyl groups (e.g. 16, $20-24,36$ or 44) exhibit higher solubility in water, between tens and hundreds of grams per liter [22,23]. In some cases functionalization leads, besides to hydrophilicity, also to hygroscopic behavior. This is the case for example of polyhidroxylated fullerenes and of the $\mathrm{C}_{60}(\mathrm{ONa})_{24}$ derivative, which are not only hygroscopic but even form stable hydrate phases upon prolonged exposure to air [24,25]. 
It is worth mentioning that, at the other extreme, organic functionalization of $\mathrm{C}_{60}$ can also be employed to obtain amphiphilic derivatives, [20] or even to enhance the hydrophobicity of pristine fullerene: for example, $\mathrm{C}_{60}$ functionalized with three eicosyloxy aliphatic chains form hierarchically self-assembled structures with superhydrophobic surfaces [26].

iii) Film processability from solution. Implementation of an organic material as sensor or solid-state catalyst, or for electronic and optoelectronic applications is only commercially viable if the organic material is easily processable in thin-film form. In order to deposit films and coatings of fullerenes using low-cost solution methods (e.g. spin-coating, solvent-casting, melt extruding, etc.), solutions in volatile or viscous solvents are required. This is hardly achievable with pristine fullerenes due to their low solubility in most solvents [1]. Functionalization allows dissolving fullerene derivatives in volatile solvents, and to achieve much higher solubility in conventional solvents than that of pure $\mathrm{C}_{60}$. This in turn allows depositing organic films without resorting to the high vacuum deposition methods usually employed to deposit pristine fullerenes. For example, thin films of $\mathrm{C}_{60}$ derivatives such as PCBM and other monoadducts $[27,28]$ may be obtained by solution casting, self-assembly or Langmuir-Blodgett techniques [29,30,31]. Such films are better suited for application in electronic and photovoltaic devices.

iv) Tailoring or enhancement of specific properties. The molecular-orbital structure of fullerene derivatives can be tuned by the introduction of heteroatoms or sideadducts, which modify the electronic energy levels, the optical properties and the chemical reactivity. Some of the functionalities that can be achieved by derivatization are, for example, enhanced biological activity and biocompatibility; modified reactivity or enhanced catalytic activity; adherence to a specific substrate; material flexibility or plasticity; enhanced optoelectronic performance. We will review some of these functionalities when discussing the solid-state applications of modified fullerenes (Sections D and E).

\section{A.2. Phenomenology of fullerene functionalization}

Buckminsterfullerene consists of sixty carbon atoms arranged on a truncated icosahedron made up of 20 hexagon and 12 pentagon rings. Each carbon has three nearest neighbors as in graphite. Of the 240 valence electrons (four for each carbon), a total of 180 (three for each atom) participate in the sigma bonds which constitute the fullerene backbone, while 60 electrons give rise to delocalized molecular orbitals. The electronic charge distribution is such that two types of $\mathrm{C}-\mathrm{C}$ edges are present in $\mathrm{C}_{60}$, namely 30 shorter "double" bonds that fuse two hexagons (6/6 bonds), and 60 longer "single" bonds that fuse a hexagon with a pentagon ( $5 / 6$ bonds).

The nanometer-size, football-shaped $\mathrm{C}_{60}$ molecule is an electron acceptor due to the strong electron affinity of $\mathrm{sp}^{2}$ hybridized carbon. This favors reduction rather than oxidation reactions, though the latter can also take place. $\mathrm{C}_{60}$ is less aromatic and less reactive than one would expect, since double bonds on the pentagon rings are usually avoided as they would lead to a shorter $\mathrm{C}-\mathrm{C}$ bond length resulting in strain in the ring structure [32]. As a consequence, fullerenes undergo reactions typical of poorlyconjugated and electron-deficient alkenes rather than those of aromatic molecules. A large number of successful methods for the organic functionalization of fullerenes exist, which have made possible the synthesis of a large variety of new molecules $[33,34]$. The quasi-spherical shape and large number of carbon atoms of the pristine fullerenes result in a unique ability to form many different products even when addition of only one reagent is considered. The derivatives may differ in the number of sideadducts but also in their relative position, leading to a pronounced isomerism. In this review we focus in particular on monoadducts, of which the prototypical and one of the most studied examples is phenyl$\mathrm{C}_{61}$-butyric acid methyl ester $\left(\mathrm{C}_{60}-\mathrm{PCBM}\right)$, and on polyadducts obtained using a single type of sidegroup of simple composition, a preeminent example of which is constituted by polyhydroxilized fullerenes $\left(\mathrm{C}_{60}(\mathrm{OH})_{n}\right.$, also known as fullerenols or fullerols). For these cases isomerism is reduced, though not completely suppressed.

Covalent fullerene derivatives can be classified according to different criteria, such as the type of chemical reaction necessary for their synthesis, the type of bond of the pristine molecule which is broken to link the sideadduct(s), the resulting bond arrangement, the number of $\mathrm{C}$ atoms/bonds involved in the functionalization or the number of sideadducts. From a molecular-structure point of view, the outcomes of the functionalization can be classified into four groups (see Fig. 1). The first three are obtained by converting one or more $\pi$ bonds of the parent fullerene molecule into $\sigma$ bonds linking a sideadduct (i.e., by converting a $\mathrm{sp}^{2}$-like carbon atom of the fullerene cage into a $\mathrm{sp}^{3}$-hybridized one); the fourth one is obtained by removing also some $\sigma$ bonds of the parent fullerene, i.e., by effectively breaking the fullerene backbone. The four possible structural outcomes are listed in the next page. The parent fullerene species undergoing derivatization can be $\mathrm{C}_{60}$, a higher fullerene, or even an endohedral fullerene containing a guest atom or a molecular cluster inside the carbon cage. Endohedral fullerenes can also be classified according to the same list, as the presence of an encapsulated moiety does not affect the type of bonding achievable on the outer surface of the carbon cage. 

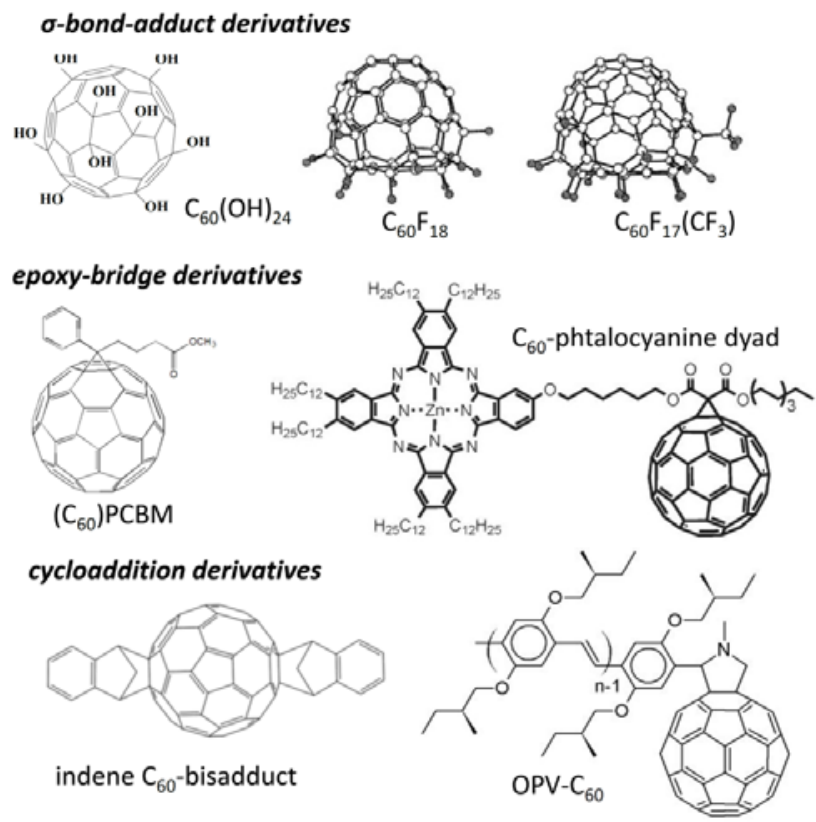

heterofullerenes and open-cage derivatives

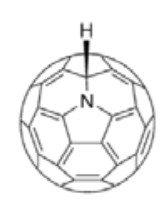

$\mathrm{C}_{59} \mathrm{NH}$
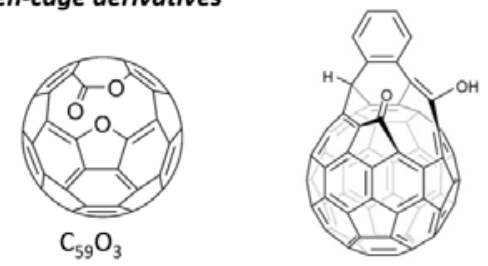

Fig. (1). Examples of the four possible types of structural outcomes of fullerene functionalization.

i) Addition of a sideadduct via a single covalent bond to a single carbon. In this case a single $\sigma$-bond is formed between a carbon atom of the fullerene cage and an atom of the sideadduct (via a reduction or oxidation reaction), so that each adduct is covalently linked to only one carbon of the fullerene cage. The maximum number of adducts depends on the characteristics of the sidegroup: for the very small $-\mathrm{H}$ and -F sideadduct (fulleranes and fluorofullerenes), it can go from 1 up to 60 (total number of carbons in the $\mathrm{C}_{60}$ cage); for a diatomic group such as $-\mathrm{OH}$ (fullerol), the highest reported number of sideadducts is 44 ; for larger atoms or groups, such as $-\mathrm{Br},-\mathrm{Cl},-\mathrm{CH}_{3}$, the number of sideadducts can be at most 24 (maximum number of non-adjacent side groups). One should notice that the distribution of sideadducts needs not be symmetric, nor the carbon cage retain its quasi spherical shape (see the upper part of Fig. 1)

ii) Addition by $\mathrm{C}-$, $\mathrm{O}-$, or $\mathrm{N}-$ epoxy bridging $([2+1]$ cycloaddition). In this case two fullerene carbons are linked to the same atom of a sideadduct. Also in this case there is a limit to the maximum number of epoxy additions. For epoxydized $\mathrm{C}_{60} \mathrm{O}_{n}$, the simplest derivatives containing epoxy bridges, the maximum number of adducts is 18 [35]; for $[2+1]$ cycloaddition to carbon atoms of aromatic sideadducts, the largest reported number of adducts is six, although the most common cases are those of mono- or bisadducts (e.g. PCBM and bis-PCBM).

iii) $[2+n]$ Cycloaddition with $n \geq 2$. In this case, two fullerene carbons are linked to two or more different atoms of the same sidegroup, forming a ring structure of four or more atoms. The two carbon atoms of the fullerene unit always constitute the edge shared by two hexagonal faces; there are 30 such edges ([6,6] double bonds) in total in pristine $\mathrm{C}_{60}$. Addition of e.g. up to six cyclopentadienes (by $[2+4]$ cycloaddition) or six benzyne (by $[2+2]$ cycloaddition) has been reported. A prominent example of cycloaddition with an odd number of atoms in the ring is that of fulleropyrrolidines, characterized by a $[2+3]$ cycloaddition structure.

Large sideadducts are usually linked to the fullerene moieties via epoxy additions (ii) or $[2+n]$ cycloadditions (iii) $[17,36,37,38]$, though in some cases also single-bond linking (i) has been employed [39].

iv) Substitution of one or more carbon atoms with atoms of a different element or with whole groups/moieties. The elemental substitution of fullerene carbon atoms gives rise to heterofullerenes, the most common of which are boron- and nitrogen-substituted fullerenes (borafullerenes and azafullerenes) [40,41]. In some cases some of the fullerene carbons are removed rather than substituted, resulting in socalled open-cage fullerenes where functionalization is accompanied by partial disruption of the carbon backbone. The carbon cage is "opened" by successive chemical reactions referred to collectively as "fullerene surgery", leading to covalent linking of heterospecies and even oligomers to adjacent carbon atoms of the parent fullerene $[42,43,44,45,46]$.

It is worth mentioning two more types of "derivatization" products of $\mathrm{C}_{60}$ which are not obtained by covalent synthetic chemistry, but which nonetheless constitute important examples of organo-fullerene systems. The first one is represented by non-covalently bonded complexes of fullerenes with different molecules ranging from porphyrines to light harvesting dendrimers, to solvates and hydrates of $\mathrm{C}_{60}$ or higher fullerenes [47]. A second one is represented by all-carbon nanotubes-fullerene macromolecular hybrids such as peapods [48] and covalently-linked hybrids [43], and all$\mathrm{C}_{60}$ polymer chains and networks observed in solid $\mathrm{C}_{60}$ phases. If peapods are an extreme example of non-covalently bonded complex, the latter two can be considered very special examples of either single-bond or cycloadditionbonded fullerene derivative or even of heterofullerenes, depending on their structure. About all-fullerene oligomers or polymers, these result via the formation of covalent bonds between neighboring $\mathrm{C}_{60}$ molecules in condensed phases: for example, fullerite undergoes self-polymerization under UV or visible light irradiation (photopolymerization) [49,50,51], by heating under applied pressure [52], or upon exohedral doping with some alkali and alkaline-earth elements [53,54]. These methods lead to the formation of $\mathrm{C}_{60}$ dimers $[55,56]$, 
1D-polymer chains [57,58], and even 2D and 3D polymer networks $[59,60]$.

\section{B) SOLID-STATE STRUCTURE AND PHASE TRANSITIONS}

The determination of the solid-state structure of fullerene derivatives is hampered in many cases by a variety of factors. Oligomers with fullerene units covalently linked to them do not usually exhibit crystalline order, as is the case for polymers in general; many smaller derivatives do not allow solid-state structural determination due to their high molecular isomerism and/or structural polymorphism; finally, even when for molecules which can be produced and purified in large enough quantities to allow investigation by diffraction techniques, the determination of their structure is hampered by the large concentration of defects, and by the static or dynamic orientational disorder of the molecules.

For example, pristine fullerite exhibits a rotator phase of freely spinning molecules at ambient temperature. Due to such rotational freedom, only the time-averaged symmetry of the solid may be defined, corresponding to the packing of perfect spheres (rather than truncated icosahedra) into a facecentered cubic $(f c c)$ lattice (see also subsection B.3). At low temperature, where the molecular rotations are frozen and thus the orientation of the molecules becomes important, the lattice structure can be described as a simple cubic (sc) cell with four nonequivalent molecules each with a different orientation [61]. The functionalization of the $\mathrm{C}_{60}$ molecule results in derivatives with higher number of degrees of freedom and thus more complex molecular and orientational dynamics. As a consequence, while simple diffraction studies of fullerene solids allows determining the overall lattice symmetry (space group), that is, the positions of the centers of mass of the individual fullerenes, a full structural characterization can only be obtained with refinement of high-resolution single-crystal data, due to the (static or dynamic) orientational disorder of the molecules. Information on the molecular rotational dynamics must be obtained with separate techniques such as NMR or dielectric spectroscopy (see subsection B.3).

Structural characterization of endohedral fullerenes is usually hampered by their high isomerism and reactivity. A structural study of the endohedral $\mathrm{Kr} @ \mathrm{C}_{60}$ species has shown that the presence of the noble gas atom inside the $\mathrm{C}_{60}$ molecule does not affect the resulting lattice structure [62], as may be expected since the endohedral species does not modify in this case the intermolecular interactions. This is however not the case in many other endohedral species in which charge transfer to the fullerene cage takes place, resulting e.g. in the formation of polymer phases, as in $\mathrm{Li} @ \mathrm{C}_{60}$ [63], or in nonzero molecular electrical and even magnetic dipole moment, as in lanthanide endofullerenes [64]. This Section focuses on the lattice symmetry, orientational properties and morphology of exohedrally functionalized fullerenes and non-covalent fullerene-organic complexes.

\section{B.1. Effect of covalent functionalization and cross-linking on the solid-state structure and morphology}

In covalently functionalized fullerenes, single atoms or larger adducts are chemically bonded to the carbon cage. The resulting modification of the solid-state structure with respect to pristine fullerite depends on the size and number of the adducts. For example, the lattice symmetry of both $\mathrm{C}_{60}$ epoxide $\left(\mathrm{C}_{60} \mathrm{O}\right.$, obtained by addition of a single oxygen atom) and of $\mathrm{C}_{61} \mathrm{H}_{2}$ (addition of a methylene group) is $f c c$ at room temperature, like that of pristine fullerite, as the addition of an epoxide or methylene group represents a relatively small steric modification of the $\mathrm{C}_{60}$ molecule $[65,66,67,68]$. The $f c c$ phase of these derivatives, like that of pristine fullerite, displays dynamic orientational disorder; however, the sideadducts are statistically distributed in the octahedral and tetrahedral voids of the $f c c$ lattice and the rotations are not those of a free rotor but rather involve jumps between positions of minimum steric hindrance [65].

With increasing number or polarity of the sideadducts, the (van der Waals) interactions between the carbon cages becomes less important compared to dipolar interactions or interactions between adducts. For example, some halogenated or hydroxylated fullerenes are asymmetric and polar, leading to highly anisotropic intermolecular reactions resulting in lower-symmetry crystal structures (e.g. monoclinic in the polar $\mathrm{Br}_{6} \mathrm{C}_{60}$ derivative [69]). As the number of adducts increases, the fullerene derivative recovers a more symmetric structure and isotropy, leading to higher crystal symmetries (e.g. bcc in the $\mathrm{C}_{60} \mathrm{H}_{36}$ fullerane [70]). The crystal structure formed by $\mathrm{C}_{60}$ derivatives with larger sideadducts is in general not unique. For example, PCBM crystals grown from solution display very different structural arrangements, with symmetry ranging from triclinic to hexagonal depending on both the choice of solvent [71,72] and the growth rate of the crystals [73]. Fullerene derivatives with tail-like sideadducts can form bilayer lamellar structures similar to those observed in blockcopolymers $[26,74]$.

Relatively few solid-state structural studies exist on heterofullerenes, due to the fact that many could not yet be isolated. Among heterofullerenes, the best known ones are azafullerene derivatives. The replacement of a carbon atom of the fullerene cage with a nitrogen atom leads to the excess of one electron in the molecular orbital configuration; as a result, stable azafullerenes either exist as dimers, as in $\left(\mathrm{C}_{59} \mathrm{~N}\right)_{2}$, or they are stabilized by addition of electrodeficient sidegroups, as in $\mathrm{C}_{59} \mathrm{NH}$ (see Fig. 1), or via the formation of open-cage-like structures [40]. In the first two cases it is a carbon atom next to the nitrogen heteroatom (and not the heteroatom itself) which binds the adduct. In the case of the $\left(\mathrm{C}_{59} \mathrm{~N}\right)_{2}$ dimers, synchrotron X-ray diffraction measurements have shown that they crystallize in a monoclinic structure (space group C2/m) between 278 and $500 \mathrm{~K}$ [75].

As mentioned at the end of subsection A.2, in the solid state covalent bonds can also form between pristine $\mathrm{C}_{60}$ molecules, e.g. by irradiation, application of pressure, or 
intercalation with certain alkali and alkaline-earth elements, resulting in all-fullerene oligomers and polymers. While pristine $\mathrm{C}_{60}$ fullerite exhibits a rotator phase at room temperature, this is not the case for polymerized samples, since intermolecular linking occurs via $[2+2]$ cycloaddition bonds that connect rigidly four carbon atoms sitting on two next-neighbour fullerenes, so that the molecular orientations are fixed. Atomic force microscopy studies of photopolymerized $\mathrm{C}_{60}$ films allowed observation of different surface morphologies depending on the temperature at which photopolymerization takes place, with the film surface either composed of dimers and trimers only or presenting a herring-bone structure with longer oligomer chains (up to six molecular units) [51].

Besides its impact on the molecular-scale arrangement and lattice structure, covalent functionalization can be exploited to control the morphology of the clusters by tuning supramolecular interactions. As an example, alkylconjugated fulleropyrrolidine derivatives form supermolecular clusters with morphologies resembling spheres, conical shells, windmills, spirals, rectangular pans, flowers, stars, sponges, or fibers [26,74,76]. While the morphology can be dramatically modified when long or multiple sidechains are present [77], as in the case of liquidcrystalline fullerenes where the anisotropic structure is mostly determined by the sideadducts $[38,78,79,80]$, it should be noted that a rich variety of forms are also obtained from solutions of pristine $\mathrm{C}_{60}$ [77] (see also subsection B.3) and with $\mathrm{C}_{60}$ derivatives with relatively small adducts; in the latter case, the morphology is found to vary considerably even with relatively minor changes in the molecular structure of the adduct.[81] These studies have shown that a large variety of shapes can be obtained also while maintaining a high $\mathrm{C}_{60}$ volume fraction, thereby preserving some of the properties of the pristine fullerene matrix.

\section{B.2. Molecular compounds, solvates and hydrates of fullerenes and fullerene derivatives}

The equilibrium (lowest energy) packing in a molecular solid normally coincides with the densest possible one. When mixed with organic molecules or small atomic clusters, therefore, fullerenes readily form van der Waals [47], polar, or ionic [82] molecular compounds (e.g. clathrates, solvates, hydrates) in which the "guest" species accommodated in the space between the globular $\mathrm{C}_{60}$ molecules so as to maximize the total density. When the guest molecules are small, the lattice structure of the molecular compounds is basically determined by the closepacking of the quasi-spherical $\mathrm{C}_{60}$ molecules, as in pure and ammonia-intercalated alkali fullerides or in $\mathrm{C}_{60}$ solvates with small solvent molecules, which exhibit vanishing or even negative excess volumes [83,84,85]. Alkali fullerides constitute the simplest example of the effect of exohedral intercalation on the crystal structure: at low alkali content the $f C C$ or $S C$ structure of pristine fullerite is preserved, while for higher alkali content a change takes place to a less compact phase (e.g. a bcc structure) [86,87]. The binary compound formed by $\mathrm{C}_{60}$ with another globular molecule, cubane $\left(\mathrm{C}_{8} \mathrm{H}_{8}\right)$, displays a structure with virtually no distortion of the pristine $f C C$ fullerite structure [88].

Organic $\mathrm{C}_{60}$ solvate crystals are formed by precipitation from solvent solutions of $\mathrm{C}_{60}$. The good solubility of $\mathrm{C}_{60}$ in aromatic hydrocarbons and small-molecule organic solvents [1] has lead to the synthesis of several solvates with different stoichiometries. The solvates display a wide range of structural motifs, summarized in panels $a$ - $d$ of Fig. 2 [47]. While small solvent molecules in low relative concentrations result in solvates with structures that deviate only slightly from the typical cubic structures observed in alkali fullerides, the formation of $\mathrm{C}_{60}$ compounds with larger solvent molecules or at high solvent concentration is usually accompanied by a change in the stacking arrangement of the fullerenesor by formation of a low-symmetry lattice.

Dense 3D packing of fullerenes (Fig. 2a) is observed in solvates with small solvent molecules at a stoichiometry of $3: 2\left(\mathrm{C}_{60}\right.$ : solvent molecules) $[89,90]$. The lattice structure is hexagonal close-packed, which represents only a minor change in the stacking pattern with respect to the $f_{C C}$ structure of pristine fullerite. $\mathrm{C}_{60}$ solvates obtained from solvents like pentane [91], 1-bromobutane [92], trichloroethane [84] and dichloroethane [85] with 1:1 stoichiometric ratio, are characterized by an intercalation motif that can be described as a stacked bilayer packing (Fig. $2 b$ ). The lattice structure can be orthorombic or hexagonal; as an example, the structural motif observed in the pentane $\mathrm{C}_{60} \quad 1: 1$ solvate is shown in panel $e$ (with the fullerene bilayers oriented vertically). Solvates with 1:2 stoichiometric ratio display lattice symmetries varying from hexagonal to triclinic which can be thought to result from the stacking of alternate layers of fullerenes and guest molecules (Fig. 2c). This packing motif is for example observed in 1:2 solvates of $\mathrm{C}_{60}$ with tetragonal molecules $\left(\mathrm{P}_{4}, \mathrm{CCl}_{4}\right)$. Larger solvent molecules can result in a framework structure such as
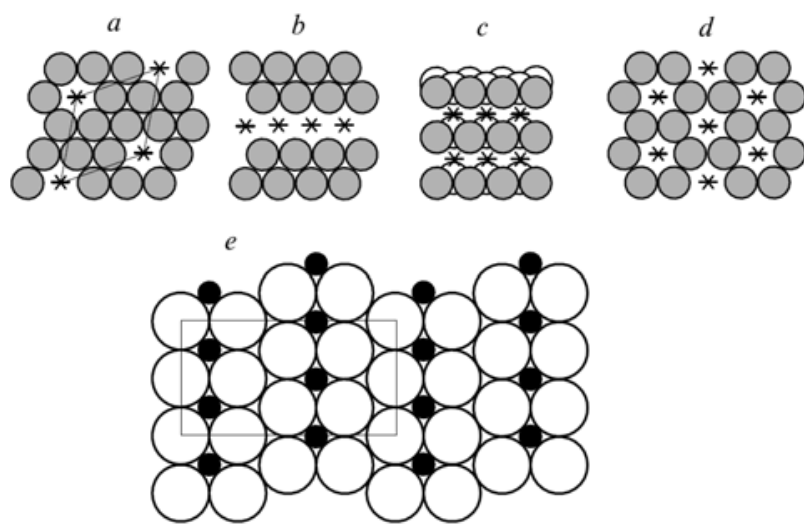

Fig. (2). The main packing motits observed in binary solvates and molecula complexes of $\mathrm{C}_{60}$ : $(a)$ dense close-packing; $(b)$ stacked $\mathrm{C}_{60}$ bilayers separated by intercalant layer; $(c)$ close-packed alternate layers; $(d)$ framework. $(e)$ White or grey circles represent $\mathrm{C}_{60}$ molecules, stars solvent molecules, and black filled circles pentane molecules. Adapted with permission from Russ. Chem. Rev., 2004, 73, 455. 
depicted in Fig. $2 d$. At very high stoichiometric ratios of the solvent, the abundance of the solvent leads to the formation of solvent-rich islands in which the $\mathrm{C}_{60}-\mathrm{C}_{60}$ van der Waals interactions are negligible, as demonstrated e.g. using $\mathrm{CCl}_{4}$ and $\mathrm{CBrCl}_{3}$ with a fullerene-solvent ratio of 1:12 [93,94,95]. Ternary molecular complexes can also be formed (e.g. when a second species is dissolved in the solvent together with fullerene); the increased complexity gives rise to yet more complicated types of packing.[47] Besides having an obvious impact on the lattice arrangement, cocrystallization of $\mathrm{C}_{60}$ with organic species such as solvent molecules lead to specific macroscopic morphologies of the resulting crystallites.

A special class of binary complexes is that of hydrates. These materials may be obtained from aqueous solution but also by prolonged exposure of a hygroscopic fullerene derivative to humid atmosphere. Indeed, functionalization of $\mathrm{C}_{60}$ with hydrophilic groups leads not only to enhanced solubility in water but also to hygroscopic behavior, as is the case of fullerol $\mathrm{C}_{60}(\mathrm{OH})_{24}$ and the related sodium oxofullerene compound of formula $\mathrm{C}_{60}(\mathrm{ONa})_{24}[24,25,96]$. Hydration of hydrophilic fullerenes may lead to the formation of crystalline hydrates with larger lattice spacing and different symmetry than those of the pure (water-free) derivative [25]. As an example, in Fig. 3 we show the powder X-ray diffraction of pure $\mathrm{C}_{60}(\mathrm{ONa})_{24}$ and of its hydrate of stoichiometry $\mathrm{C}_{60}(\mathrm{ONa})_{24} \cdot 16 \mathrm{H}_{2} \mathrm{O}$. The diffraction pattern of the pure material, which is in fact obtained by heating the hydrate to high temperature, exhibits a much higher scattering background and significantly broader peaks, indicating only partial order and smaller grain size compared to the hydrate (as may be expected considering both the loss of water volume and the possible formation of defects upon the structural change). Moreover,

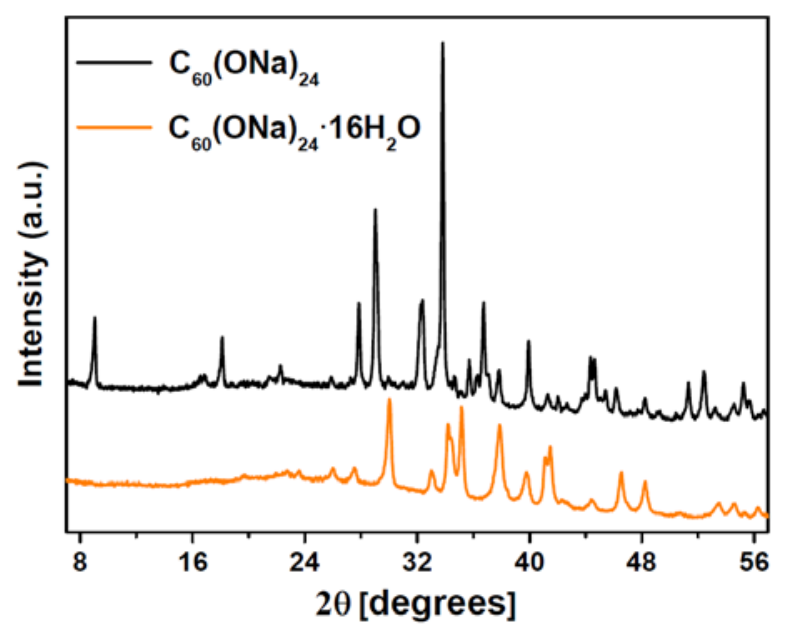

Fig. (3). Powder X-ray diffraction patterns of the $\mathrm{C}_{60}(\mathrm{ONa})_{24} \cdot 16 \mathrm{H}_{2} \mathrm{O}$ hydrate (obtained as crystalline powder after aqueous synthesis) and of the pure $\mathrm{C}_{60}(\mathrm{ONa})_{24}$ derivative (obtained by heating the hydrate to $423 \mathrm{~K}$ ). The patterns are normalized to acquisition time and displayed with an offset for clarity. Reprinted with permission from J. Phys. Chem. C 119, 685-694. Copyright 2015 American Chemical Society. the pure material does not exhibit any clear peak below $2 \theta=$ $20^{\circ}$ and displays main diffraction peaks at much higher scattering angles than the hydrate. This indicates that the pure material is characterized by a smaller first-neighbor distance due to the loss of the structural water.

The X-ray diffraction pattern of the $\mathrm{C}_{60}(\mathrm{ONa})_{24} \cdot 16 \mathrm{H}_{2} \mathrm{O}$ hydrate could be indexed by pattern-matching as a monoclinic P2/m phase with unit cell volume of $1126.5 \AA^{3}$. Such value is similar to that of other fullerene derivatives and solvates such as $\mathrm{C}_{60} \mathrm{Br}_{24}\left(\mathrm{Br}_{2}\right)_{2}, \mathrm{C}_{60} \mathrm{~F}_{36}$ or $\mathrm{C}_{60} \mathrm{~F}_{48}$ [97,98]. The authors of [25] report that it was instead not possible to obtain a reliable indexing for the pure material, perhaps due to the low intensity and relatively large width of the lowangle diffraction features in the diffraction pattern. This is not necessarily a problem of purity of the material: as it occurs for $\mathrm{C}_{60}$ powders obtained from solutions and $\mathrm{C}_{60}$ solvates in which solvent molecules remain trapped into the re-built lattice [99], the material resulting from the dehydration process may contain structural defects (such as the well-known solvent-induced stacking faults) which produce broadening, shift or asymmetry of diffraction peaks that vary for different Miller indexes, thus hampering indexation [85]. These studies give an idea of the inherent difficulty of determining the crystal structure of fullerene derivatives, due both to defects in the lattice structure and to the orientational disorder.

As mentioned at the beginning of this subsection, also polar (charge-transfer) molecular compounds exist, which are usually obtained from solution of fullerenes and electrondonor species in a solvent common to both organic species $[47,82,100]$. One of the most studied examples is the salt formed by $\mathrm{C}_{60}$ with tetrakisdimethylaminoethylene (TDAE), where one electron is transferred from TDAE to the LUMO orbital of Buckminsterfullerene. This organic salt, which only contains elements of the first raw of the periodic table, is insulating and displays a ferromagnetic transition at $\mathrm{T}_{\mathrm{c}}=$ $16 \mathrm{~K}$ [101]. The magnetic moments are due to the unpaired electrons on the $\left(\mathrm{C}_{60}\right)^{-}$ions, which are Jahn-Teller-distorted into an elongated shape so that the degeneracy of the $C_{60}$ LUMO level is removed and a "belt-like" distribution of the spin density results, with the maximum at the equator and the minimum at the poles [102]. Ferromagnetic coupling is due to the exchange interaction between the LUMO electrons of next-neighbour molecular anions, whose elongated axes are mutually orthogonal to one another [103].

The cobaltocene salt of a monoadduct $\mathrm{C}_{60}$ derivative (1(3-aminophenyl)- $1 H$-methano-fullerene) displays one of the highest ferromagnetic critical temperature reported in $p$ electron systems. Although the neutral donor contains a transition metal atom $(\mathrm{Co})$, this carries no net spin in its oxidized state, so that the magnetic moments reside entirely on the fullerene units; also in this case magnetism is a consequence of exchange interactions between neighboring fullerene derivatives [104]. Some ammoniated alkali fullerenes also display $p$-electron magnetism of the carbon 
cages; these materials display antiferromagnetic phases stable up to liquid-nitrogen temperatures [105].

\section{B.3. Orientational phase transitions in fullerene solids}

As mentioned at the beginning of this Section, in pristine fullerite the molecules rotate very rapidly at room temperature, resulting in an orientationally disordered $f c c$ structure with $F m \underline{3}$ m symmetry. Below $260 \mathrm{~K}$ this free-rotor motion is reduced to a ratcheting motion between two preferred orientations [106,107]. Such phase transition displays a temperature hysteresis of $5 \mathrm{~K}$, and takes place at unusually high temperature compared with other systems (for example, in deuterated methane $\mathrm{CD}_{4}$, the analogous transition takes place at $20.4 \mathrm{~K}$ ). The merohedral reorientational motion of the $\mathrm{C}_{60}$ molecules finally freezes out at a glassy transition at $90 \mathrm{~K}$, below which the lattice structure is simple cubic with $\mathrm{Pa} \underline{3}$ symmetry $[61,108]$.

It is worth mentioning that multiple sublimations, formation of $\mathrm{C}_{60}$ crystals from solution, or decomposition of solvates can lead to an hexagonal closed packed (hcp) structure instead of an $f c c$ one [83,109,110,111]. The hcp structure differs from the $f c c$ one not only due to the different packing of the hexagonal layers, but also in terms of the orientational dynamics, which in the hcp structure appears to be cylindrical (uniaxial) [110] rather than "spherical" as in the $f c c$ free-rotor structure. Deposition of $\mathrm{C}_{60}$ from solutions and vapor-driven crystallization not only determine the microscopic molecular arrangement, but can also be used to control the sample morphology; a rich variety of forms can be obtained for pure fullerene crystallites, ranging from nanowhiskers to hexagon plates, to filled and hollow nanospheres [77,111,112].

Since the orientational order in $\mathrm{C}_{60}$ is mainly due to van der Waals $(\pi-\pi)$ interactions between adjacent molecules, any perturbation to the van der Waals network will affect the symmetry of the structure and alter the nature of rotational transitions. Examples of simple derivatives that display orientational transitions are $\mathrm{C}_{60} \mathrm{O}$ and $\mathrm{C}_{61} \mathrm{H}_{2}$ (of the latter, two isomers exist, the 6,6-cyclopropane isomer and the more open 6,5-annulene isomer). The annulene isomer of $\mathrm{C}_{61} \mathrm{H}_{2}$ and $\mathrm{C}_{60} \mathrm{O}$ both exhibit transitions analogous to pristine fullerite; however, in the high-temperature $f C c$ phase the molecules do not behave as free rotors due to the fact that the adducts must occupy interstitial voids to avoid steric hindrance (the methyl adduct can only occupy the larger octahedral voids, while at room temperature the epoxy oxygen occupies a octahedral void roughly two thirds of the time and a tetrahedral void one third of the time). This results in an increase of the plastic transition temperature from $260 \mathrm{~K}$ in pristine $\mathrm{C}_{60}$ to $278 \mathrm{~K}$ in $\mathrm{C}_{60} \mathrm{O}$ and to $290 \mathrm{~K}$ in $\mathrm{C}_{61} \mathrm{H}_{2}$ annulene. It has been shown $[67,68]$ that the increase in the transition temperatures originates from the lower entropy of dynamically-disordered phases of these fullerene derivatives with respect to fullerite, which is again due to the fact that the adducts can only occupy interstitial voids. This suggests that also in pristine fullerite the orientational transitions are entropy-driven, and in the case of $\mathrm{C}_{60} \mathrm{O}$ it indicates that the stronger (dipolar) intermolecular interactions due to the presence of the epoxy moiety have instead a negligible effect on the transition temperature.

The cyclopropane isomer of $\mathrm{C}_{61} \mathrm{H}_{2}$ displays a different phase diagram than the annulene isomer. In particular, the low-temperature structure is not $\mathrm{Pa} \underline{3}$ (as in the simple cubic phases of the other two derivatives and of pristine fullerite), but is instead a low-symmetry orthorhombic lattice in which $\mathrm{a} \approx \mathrm{b}<\mathrm{c}$. The orientational melting takes place in this system via a two-step transition around 198-213 K [66]. The $\mathrm{C}_{61} \mathrm{H}_{2}$ cyclopropane is the simplest derivative that displays a pronounced deviation from the typical behavior of pristine $\mathrm{C}_{60}$. The difference with the annulene isomer might arise from the slightly larger separation of the methyl group from the center of the carbon cage or from its different position on the cage [66]. The presence of larger sideadducts (as in $\mathrm{C}_{60}\left(\mathrm{Os}_{4}\right)$ (4-tert-butylpyridine $\left.)_{2} \quad[113,114]\right)$ or of stronger intermolecular interactions (as in alkali fullerides [6,115]) hinders molecular rotations, generally resulting in an increase of the plastic transition temperature.

Intercalation compounds of $\mathrm{C}_{60}$ with guest molecules (molecular complexes) display orientational transitions that may be close to or far from those of pristine fullerite depending on the guest species. For example, the low- and high-temperature structures of $(\mathrm{CO})_{\mathrm{x}} \mathrm{C}_{60}$ are almost identical to those of fullerite, with the $\mathrm{CO}$ molecules confined to the octahedral voids [116]. The intercalation of atmospheric molecules $\left(\mathrm{O}_{2}, \mathrm{~N}_{2}\right)$ leads similarly to only slight modifications of the orientational transitions: the rotation of the fullerenes is partially impeded by the presence of molecular oxygen, which constrains the rotation to a merohedral motion rather than the free-rotor motion of $f c c$ fullerite [117]. Larger deviations are observed in solvates with bigger molecules, as in cocrystals of fullerenes with cyclic $\mathrm{S}_{8}$ sulfur rings. In $\mathrm{C}_{60} \cdot 2 \mathrm{~S}_{8}$, for example, the X-ray diffraction pattern reveal a monoclinic lattice of apparently static fullerene units, while NMR experiments indicate that all carbon atoms are magnetically equivalent. The two observations can only be reconciled by assuming that the $\mathrm{C}_{60}$ molecules undergo fast jumps between symmetry-equivalent orientations within the solvate [118]. The $\mathrm{C}_{60} \cdot 2 \mathrm{~S}_{8}$ solvate therefore also displays merohedral disorder rather than freerotor motion. Orientational dynamics is observed also in the higher-fullerene solvate $\mathrm{C}_{70} \cdot 6 \mathrm{~S}_{8}$, with however less rich phase behavior compared to pure $\mathrm{C}_{70}$ [119].

An interesting case is that of the fullerene-cubane 1:1 solvate mentioned at the beginning of the previous subsection. The shape of the cubane is somehow complementary to that of the $\mathrm{C}_{60}$ molecules, so that this molecule fits almost perfectly in the octahedral voids of a slightly enlarged $f c c$ lattice of $\mathrm{C}_{60}$ molecules [88]. As a result, the free rotor phase of pure $\mathrm{C}_{60}$ is preserved in this solvate down to $140 \mathrm{~K}$. The reduction of the transition temperature is likely due to the weakening of the $\mathrm{C}_{60}-\mathrm{C}_{60}$ interactions brought about by the lattice expansion. 


\section{C) ELECTRONIC AND RELATED PROPERTIES}

Because neutral molecules have a totally filled valence shell and orbital overlap of neighboring molecules is small even in the solid state, pure molecular materials exhibit narrow electronic bands which at zero Kelvin are either totally filled (e.g. the valence band) or totally empty (as e.g. the conduction band). This results in a semiconducting or insulating character of molecular solids. Fullerenes and their derivatives also form electrically insulating or at best semiconducting phases, which as such display poor charge transport and poor heat transport properties.

\section{C.1. Energy levels and band formation in the solid state}

Fig. 4 presents a visual comparison of the energy position of the HOMO and LUMO orbitals of several $\mathrm{C}_{60}$ derivatives $[12,120,121,122]$. Although the symmetry of a derivative is generally lower than that of the parent fullerene, many molecules retain the threefold degeneracy of the LUMOderived band of $\mathrm{C}_{60}$. The energy of the HOMO and LUMO electronic levels may be estimated by calculation, cyclic voltammetry measurements, or electron spectroscopy; values obtained with different methods usually show good agreement [12,123]. As may be observed, in covalent $\mathrm{C}_{60}$ derivatives both levels are generally shifted to less negative energies compared to pristine $\mathrm{C}_{60}$, and this is true also for derivatives obtained by the less common fullerene oxidation reactions [120]. The higher energy position of the molecular electronic levels of functionalized $\mathrm{C}_{60}$ may be expected, as valence electrons are less delocalized in the derivatives than in pristine $\mathrm{C}_{60}$, resulting in electronic tighter confinement and thus higher energy. This effect is due fundamentally to the modification of the electron distribution induced by the formation of covalent bonds to the sideadducts, and does not depend on the linear size of the adducts, as shown for

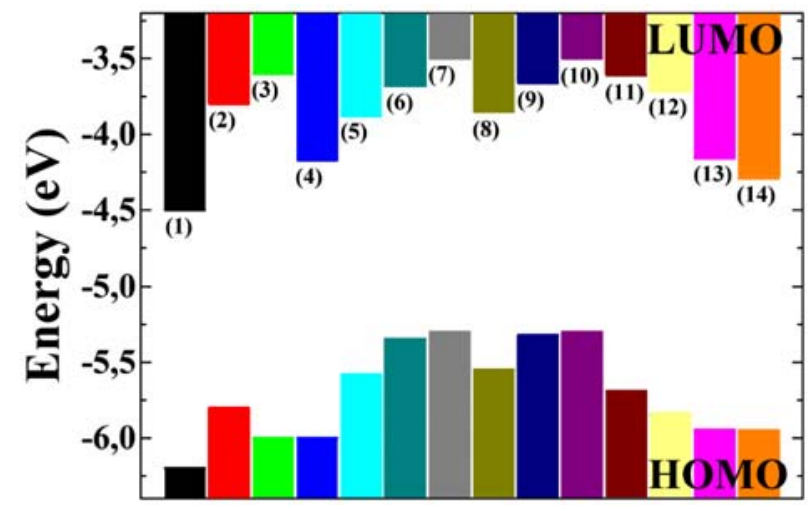

Fig. (4). HOMO and LUMO levels (with respect to the vacuum level) of for $\mathrm{C}_{60}$ (1) and thirteen $\mathrm{C}_{60}$ derivatives used as electron acceptors (n-type organic semiconductors): (2) PCBM (Fig. 1), (3) bis-PCBM, (4) Ketolactam-1 monoadduct (from [12]); (5) indene monoadduct, (6) indene bisadduct (Fig. 1), (7) indene trisadduct, (8) o-xylene monoadduct, (9) 0 xylene bisadduct, (10) 0 -xylene trisadduct (from [120]); (11) alkoxylated PCBM $\left(\mathrm{C}_{60}\left(\mathrm{OCH}_{3}\right)_{4}-\mathrm{PCBM}\right)$, (12) aziridino form of alkoxylated PCBM $\left(\mathrm{C}_{60}\left(\mathrm{OCH}_{3}\right)_{4}-\mathrm{N}-\mathrm{PCBM}\right)$ (from [121]), (13) methanoPCBM $\left(\mathrm{CH}_{2}-\mathrm{PCBM}\right)$, (14) Bis-benzyl- $\mathrm{C}_{60}$ (from [122]) example in the case of the [2+3]fulleropyrrolidine $\mathrm{C}_{60}$ derivatives [123]. Fulleropyrrolidines display almost identical HOMO and LUMO electron distributions, which are moreover very similar to those of the [2+1]epoxy-bonded $\mathrm{C}_{60}$-PCBM derivative. On the other hand, it may be observed in Fig. 4 that the bandgap (energy separation between the LUMO and HOMO levels) of the fullerene derivatives can be larger or smaller than that of the parent molecule, resulting in a modification of the optical properties.

Electron-based spectroscopy techniques (direct and inverse photoemission, electron-tunnelling spectroscopy) can be employed to probe the occupied and unoccupied electronic density of states in fullerene solids $[12,58,124,125,126,127,128]$. An example is given in Fig. 5, which shows the valence-band photoemission and inverse photoemission spectra of films of two $\mathrm{C}_{60}$ derivatives, namely the PCBM bisadduct and the Ketolactam-1 monoadduct [12]. Each peak corresponds to an electronic band derived from a molecular orbital, and its position reflects the energy of that band relative to the vacuum level. It is important to note that in electronic spectra the width of the features does not reflect that of the corresponding electronic bands, which are instead much narrower. The large width of the spectral features is mostly due to FranckCondon broadening (i.e., to phonon satellites) with a less important contribution of band dispersion effects. Evidence for such effects is provided by several electron spectroscopy studies on $\mathrm{C}_{60}$ films, both for the occupied and empty states $[128,129,130,131]$.

\section{C.2. Heat and charge transport}

As mentioned at the beginning of this Section, fullerenes and their derivatives form electrically insulating or semiconducting solids. If heat conduction is generally poor in electrical insulators, it is even lower in molecular solids due to the local (single-molecule) nature of the lattice vibrations, as evidenced in early studies on pristine fullerite

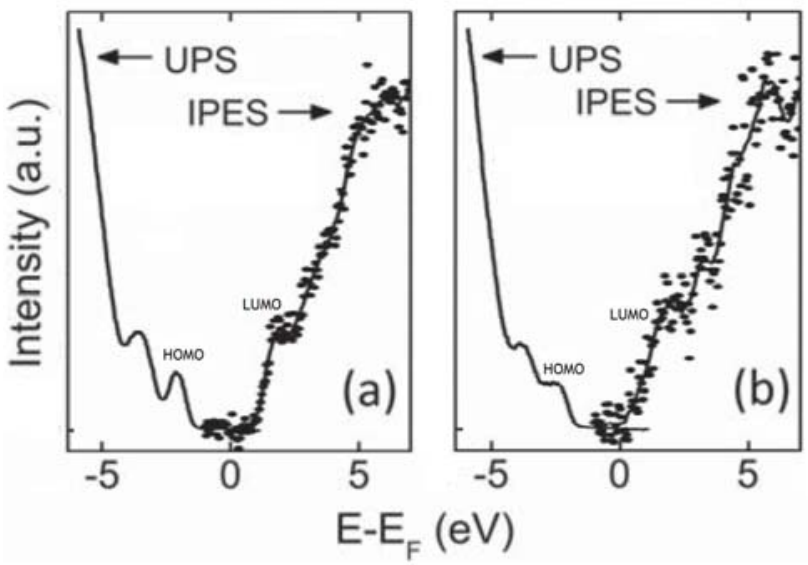

Fig. (5). Ultraviolet photoelectron spectra (UPS) and inverse photoemission spectra (IPES) of thin films of two $\mathrm{C}_{60}$ derivatives, namely (a) bis-PCBM and $(b)$ Ketolactam-1. The energy position is relative to the Fermi level $\left(\mathrm{E}_{\mathrm{F}}\right)$. Reprinted with permission from J. Appl. Phys. 110, 014506. Copyright 2011, AIP Publishing LLC. 

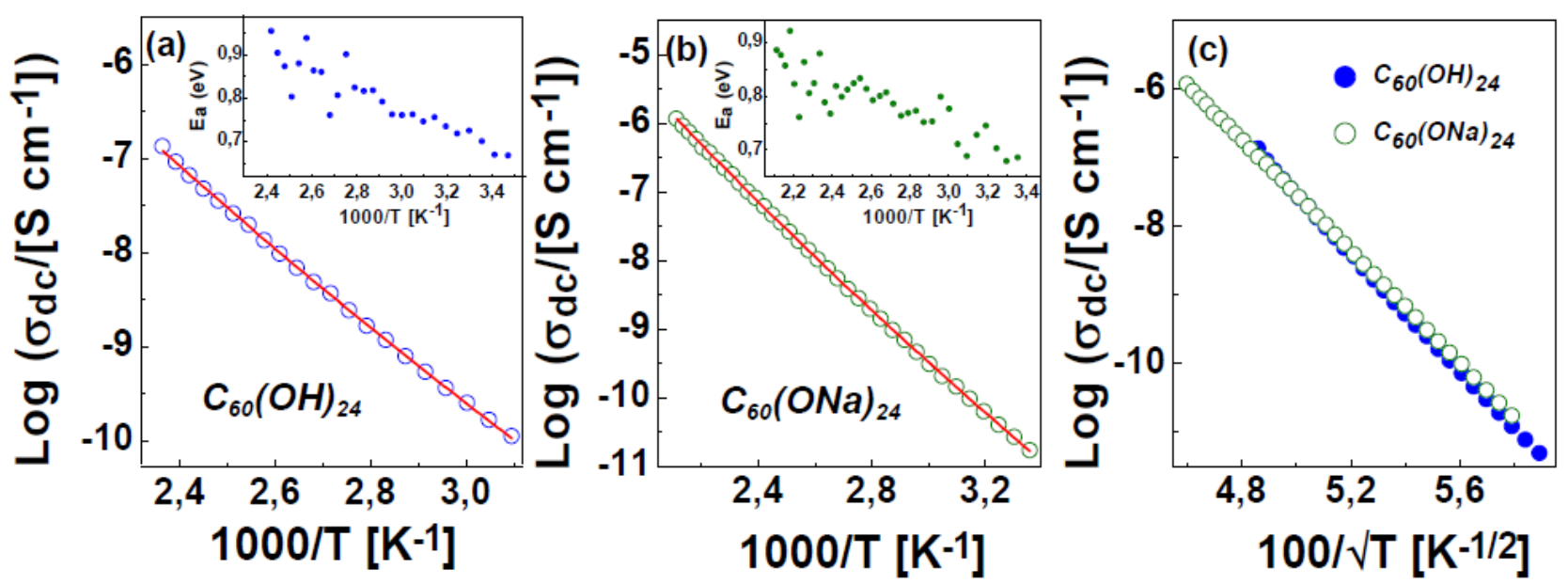

Fig. (6). Arrhenius plot of the $\sigma_{\mathrm{dc}}$ of fullerol $\left(\mathrm{C}_{60}(\mathrm{OH})_{24}, a\right)$, measured by dielectric spectroscopy upon cooling from 423 to $323 \mathrm{~K}$, and of sodium oxofullerene $\left(\mathrm{C}_{60}(\mathrm{ONa})_{24}, b\right)$, measured upon cooling from 473 to $303 \mathrm{~K}$. Markers are experimental points and continuous lines are power law fits (see the text). (c) Plot of $\log \left(\sigma_{\mathrm{dc}}\right)$ versus $100 / \sqrt{ } T$ for both derivatives, where a linear dependence can be observed. Adapted with permission from J. Phys. Chem. C 118, $12170-12175$. Copyright 2014 American Chemical Society.

[132]. Recent studies on functionalized fullerenes such as PCBM have shown $[133,134]$ that heat transport in dense films of these derivatives is even less than the theoretical lower bound for the thermal conductivity in a condensed phase (obtained considering the random walk of the vibrational energy on the time and length scales of atomic vibrations and interatomic spacing [135]), a phenomenon referred to as ultra-low thermal conductivity [134].

As to the charge transport in fullerene solids it may be due either to electrons/holes introduced by thermal excitation and by the presence of defects or impurities, as in other organic semiconductors, or else to small ionic species (usually cations) diffusing through the organic matrix. Since fullerenes and their derivatives are electron acceptors, they typically behave as n-type semiconductors in which charge carriers are electrons in the LUMO-derived band rather than holes in the HOMO-derived band (though in some cases ambipolar conduction is observed, as discussed in subsection D.1). Cations or protons, if present either as constituents or as impurities, can also contribute to and even dominate the overall charge transport $[24,53,136,137]$.

In order to determine the occurrence of proton conduction, the dc conductivity is often measured as function of the relative humidity (and possibly the temperature) [137], although this approach is not conclusive to discriminate between proton and ion conduction as ionic charge transport is also affected by the relative humidity [138]. Isotopic substitution experiments are better suited to identify proton conduction [139]. The identification of an electronic (as opposed to an ionic or protonic) mechanism underlying the charge transport is more straightforward, and can be achieved by performing simple temperaturedependent conductivity measurements [140]. An example is shown in Fig. 6, which exhibits the dc conductivity of $\mathrm{C}_{60}(\mathrm{OH})_{24}$ fullerol (panel $a$ ) and of the sodium-substituted fullerol-like derivative $\mathrm{C}_{60}(\mathrm{ONa})_{24}(b)$, as obtained from dielectric spectroscopy data $[96,140]$.

The data are shown as Arrhenius plots $\left(\log \left(\sigma_{\mathrm{dc}}\right)\right.$ versus $1 / T$ ) in panels $a$ and $b$, and as derivative Arrhenius plots (i.e., as apparent activation energy, defined as $E_{a}=-k_{\mathrm{B}}$ $\left.\mathrm{d}\left(\operatorname{Ln}\left(\sigma_{\mathrm{dc}}\right)\right) / \mathrm{d}(1 / T)\right)$ in their insets. The Arrhenius plots of both dc conductivities display a slight positive curvature, visible from the slight increase of the apparent activation energy with increasing temperature. The experimental points were fitted assuming a power-law dependence of the form $\log \left(\sigma_{\mathrm{dc}}\right)=\mathrm{A}-\mathrm{B} / T^{n}$. The result of the fit for different samples gave a value of the power $n$ of $0.43 \pm 0.05$ for $\mathrm{C}_{60}(\mathrm{OH})_{24}$ and $0.55 \pm 0.05$ for $\mathrm{C}_{60}(\mathrm{ONa})_{24}$, respectively. These values are very close to the theoretical value of $1 / 2$ that corresponds to variable-range hopping electronic conductivity [141,142], and which is observed experimentally in a large variety of systems $[141,143,144,145]$. In contrast, ion conductors display a large variety of temperature-dependencies, from simplyactivated Arrhenius behavior with a sharp onset at a well defined temperature [136], to non-Arrhenius behavior with positive or negative curvature [146].

The $T^{-1 / 2}$ power-law dependence observed for both derivatives can be also visualized by plotting the logarithm of $\sigma_{\mathrm{dc}}$ versus $100 / \sqrt{ } T$, as shown in Fig. $6 c$. The conductivity values are very similar in both derivatives. Looking at $\mathrm{C}_{60}(\mathrm{ONa})_{24}$ data, it may be concluded that the conductivity remains purely electronic up to high temperature; indeed no ionic contribution to the conductivity is observed at least up to $525 \mathrm{~K}$ despite the high concentration of sodium species [140].

It has been shown in studies of aqueous solutions and hydrated membranes containing oligohydroxilated fullerenes $\left(\mathrm{C}_{60}(\mathrm{OH})_{x}\right.$ with $x$ between 8 and 12$)$ that the presence of these fullerene derivatives boosts the overall proton conductivity of the solution or membrane [147,148,149]. 
Similarly, an early claim of ionic conductivity in pure solidstate fullerol was made [150]. As seen in Fig. 6, the related $\mathrm{C}_{60}(\mathrm{OH})_{24}$ and $\mathrm{C}_{60}(\mathrm{ONa})_{24}$ compounds do not show exhibit protonic (or ionic) conductivity but only electronic conduction. Instead, $\mathrm{C}_{60}(\mathrm{ONa})_{24}$ exposed to humid air and the $\mathrm{C}_{60}(\mathrm{ONa})_{24} \cdot 16 \mathrm{H}_{2} \mathrm{O}$ hydrate show fingerprints of proton conduction both through surface hydration layers and by a mechanism involving the structural water [25]. These findings suggest that the fullerol derivatives $\mathrm{C}_{60}(\mathrm{OH})_{\mathrm{x}}$ and $\mathrm{C}_{60}(\mathrm{ONa})_{\mathrm{x}}$ only act as proton conductors when hydrated, that is, when water is the source of the protonic charge carriers, as found also for other fullerene derivatives [149].

While experiments on polycrystalline powders (or pellets obtained thereof) as those of Fig. 6 can only shed light on the type of conduction, absolute measurements of conductivity and mobility must be carried out in thin film form, which is also the most suitable one for electronic and optoelectronic applications [151]. We will consider the outcome of such experiments in Section D.

\section{C.3. Optical properties}

$\mathrm{C}_{60}$ absorbs strongly in the UV and visible regions of the electromagnetic spectrum, and displays in particular an absorption maximum at $620 \mathrm{~nm}$ corresponding to HOMO-toLUMO excitations to a singlet exciton state. The singlet exciton yields a faint fluorescence emission at $703 \mathrm{~nm}$ [152], but it decays preferentially into the lowest triplet excited state by intersystem crossing (with near unit efficiency). While in air the triplet state decays by excitation of molecular oxygen, in degassed solvents it undergoes nonradiative decay with a lifetime of $133 \mu$ s. Monoadducts of $\mathrm{C}_{60}$ fluoresce at $698-703 \mathrm{~nm}$ with quantum yields similar to, although usually higher than, pristine $C_{60}$ [153]. The characteristic frequencies of the lowest-energy singlet and triplet states of monoadduct derivatives are also similar to those of pristine $\mathrm{C}_{60}$ [154]. This is true despite the change in symmetry and energy separation (see Fig. 4) between the HOMO and LUMO levels.

As the fluorescence is generally weak, the color of the fullerene derivatives under white light illumination, both in powder form and in solution, is determined by the spectral profile of absorption of visible light. While the lowestenergy excitonic states are not significantly affected by functionalization, leading to similar onsets of absorption and fluorescence, the overall changes in the molecular orbital structure away from the Fermi level leads to modified absorption with respect to pristine $\mathrm{C}_{60}$ and thus to a different color of the derivative [155]. For example, the color of fullerane $\mathrm{C}_{60} \mathrm{H}_{n}$ depends on the level of hydrogenation, changing from very dark brown or black to red, and finally to very light yellow with increasing hydrogen content; similarly, the color of $\mathrm{C}_{70}$ changes from brown to green for $\mathrm{C}_{70} \mathrm{H}_{38}$ [156]. In polyhidroxylated $\mathrm{C}_{60}$ (fullerol), the color shifts from dark brown to yellowish white with increasing number of $\mathrm{OH}$ adducts. This is shown in Fig. 7, which displays color photographs of $\mathrm{C}_{60}$ and polyhydroxilated

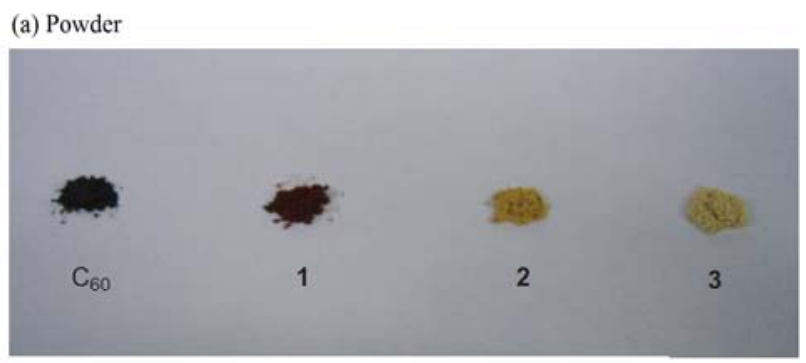

(b) Solution

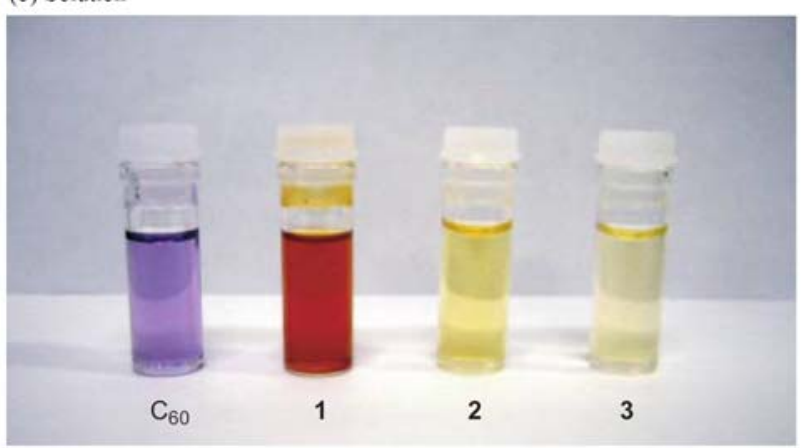

Fig. (7). Color of pristine and polyhydroxylated $\mathrm{C}_{60}$ in powder form (a) and in solution $(b): \mathrm{C}_{60}$ in toluene, $\mathrm{C}_{60}(\mathrm{OH})_{12}$ in 1,4-dioxane (1), and aqueous solutions of $\mathrm{C}_{60}(\mathrm{OH})_{36} \cdot 8 \mathrm{H}_{2} \mathrm{O}(2)$ and $\mathrm{C}_{60}(\mathrm{OH})_{40} \cdot 9 \mathrm{H}_{2} \mathrm{O}$ (3). Adapted with permission from ACS Nano 2, 327-333. Copyright 2008 American Chemical Society.

fullerene powders and of their solutions in appropriate solvents [24].

It is worth pointing out that, besides for the modification of the linear optical properties, functionalization of fullerenes has also been performed with the aim of tuning and enhancing the nonlinear optical response of the fullerene moieties $[157,158]$.

\section{D) IMPLEMENTATION IN ELECTRONIC AND OPTOELECTRONIC DEVICES}

As mentioned in the introduction, chemical functionalization of pristine fullerenes has yielded soluble derivatives that have been used to realize organic electronic $[159,160,161,162]$ and optoelectronic $[163,164,165,166,167]$ devices. The outcome of these studies will be reviewed only briefly, as several specific reviews have appeared on the (opto)electronic properties of fullerene systems.

\section{D.1. Field-effect mobility studies}

Due to their electron affinity, fullerenes and their derivatives have been investigated as electron-transporting (n-channel) materials. While air-stable organic holetransporting ( $p$-channel) semiconductors with high performance are easily obtained, air-stable $n$-channel organic materials with equivalent performance have only been achieved in the last few years, with fullerenes derivatives being one of the few examples. The difficulty of achieving air-stable organic $n$-channel semiconductors lies in the detrimental effect of adsorbed atmospheric oxidants such as $\mathrm{O}_{2}$ and water, which leads to mobility degradation by 
electron trapping $[168,169,170]$. In order to achieve airstable devices, it has been necessary to synthesize fullerene derivatives with LUMO levels lying below the trap energy of adsorbed oxidants and in particular of water [169,171], which is located at an electron affinity of approximately -4 $\mathrm{eV}$ below the vacuum level [170]. It may be seen from Fig. 2 that several fullerene derivatives which were synthesized for the purpose do indeed display LUMO levels above this threshold. Besides the higher energy of the LUMO orbital, the other beneficial effect of organic functionalization in these cases is that of introducing sideadducts which offer steric hindrance against diffusion of atmospheric oxidants below the film surface $[169,172]$.

As for the mobility values, the highest electron mobility of any small-molecule semiconductor has been measured in thin-film transistor geometry on $\mathrm{C}_{60}$ films obtained by hot wall epitaxy on a polymeric $\mathrm{BCB}$ dielectric, and it is roughly $6 \mathrm{~cm}^{2} / \mathrm{Vs}$ [173,174,175]. Solution-processed films can be achieved with derivatives such as $\mathrm{C}_{60}-\mathrm{PCBM}$ (see Fig. 1) or $\mathrm{C}_{70}$-PCBM. While functionalized fullerenes offer clear advantages in terms of low-cost film deposition, the typical electron mobility when using $\mathrm{BCB}$ as substrate is more than a decade lower than that of vapour-deposited $\mathrm{C}_{60}$ films [176,177]. $\mathrm{C}_{84}$-PCBM organic films exhibit yet lower electron mobility of about $0.5 \cdot 10^{-3} \mathrm{~cm}^{2} / \mathrm{Vs}$; however, organic FET devices based on this derivative were found to operate upon exposure to light and air during months, which represents an obvious improvement with respect to pristine fullerenes [11]. The value of the mobility and the nature of charge carriers depend not only on the derivative, but also on the choice of substrate and most importantly of the contact electrodes, as it is the alignment of electrode and organic material that determines the energy barriers for injection of charge carriers. For example, while in many cases electron (rather than hole) conduction is reported, ambipolar transport can be achieved in $\mathrm{C}_{60}$-PCBM and $\mathrm{C}_{70}$-PCBM films using gold bottom contacts on a HMDS-treated $\mathrm{SiO}_{2}$ dielectric $[178,179]$. More complex derivatives displaying ambipolar transport are conjugated polymers where each monomer is covalently linked to a fullerene unit $[36,180]$. Ambipolar transport is crucial to the performance of photovoltaic devices, where it is usually achieved by blending the electron-conducting fullerenes with hole-conducting polymers (rather than by using a single fullerene derivative) as detailed in the next subsection. The possibility of tuning the molecular orbital energies by chemical design allows modifying both the light-absorption properties and the alignment of electronic levels at interfaces [181], which can be tailored to enhance optoelectronic device performance.

\section{D.2. Optoelectronic properties of fullerene derivatives with electron-donor molecules}

In combination with electron-donating conjugated molecules, fullerene derivatives have been employed for charge-separation [182] and light-detection [183] applications that exploit their high electron affinity.
Combination with electron donors results in high quantum yields of exciton separation thanks to the deep-lying LUMO level of the fullerene species, which favors efficient photoinduced electron transfer from the donor [184,185]. For example, porphyrin-fullerene linked dyads have been extensively studied, based on the fact that porphyrins play an essential role for charge separation in natural photosynthesis $[186,187,188,189,190]$. Efficient photo-induced electron transfer to relatively long-lived charge-separated states is observed in such dyads. More sophisticated macromolecular fullerene complexes have been proposed as model systems for artificial photosynthesis, light harvesting and energy storage systems [191,192,193,194,195,196].

Following the observation of ultrafast photo-induced electron transfer from conjugated polymers to pristine $\mathrm{C}_{60}$ [197], a large number of studies have focused on the implementation of fullerenes and their derivatives (especially $\mathrm{C}_{60}$-PCBM and $\mathrm{C}_{70}-\mathrm{PCBM}$ ) in organic solar cells. While using donor-fullerene dyads as single active components provides excellent excitons dissociation yields, it also limits the interface between donating and accepting domains to the molecular size, leading to low overall efficiency. In fact, fullerene-based photovoltaic devices do not use molecular dyads as active material, but rather rely on fullerenecontaining polymer blends to enhance electron and hole transport to opposite electrodes by means of a bi-continuous interpenetrating network [198], leading to what is known as heterojunction polymer solar cells. The conjugated polymers act as electron donors, and functionalized fullerenes such as methanofullerenes and indene-fullerene derivatives [181,199,200,201] as acceptor molecules: after creation of excitons by absorption of light, they are separated by electron transfer from the donor's LUMO to the lower-lying fullerene LUMO. Under the built-in electric field caused by two asymmetric contacts, the holes are then transported through the (n-channel) polymer network and the electrons through the ( $p$-channel) fullerene derivatives to their respective electrodes. The research on fullerene bulk heterojunction solar cells has boosted their efficiency from only $0.04 \%$ in 1993 to over $9 \%$, making fullerene-based organic photovoltaics a commercially viable alternative for low-cost applications [202,203]. A lot of effort has been devoted to developing new fullerene derivatives to improve device efficiency [200], for example by exploring bis- and tris-adduct derivatives [204,205,206] or exotic functionalization [207], by choosing $\mathrm{C}_{70}$ instead of $\mathrm{C}_{60}$ for derivatization, [208] or by combining efficient charge transfer and ambipolar charge transport in a single derivative [209]. The cell efficiency depends however in a critical way on the morphology and connectivity of the blend [71], which in turns depend on a variety of factors, so that improvement of device performance by chemical design is not straightforward [203,210].

While fullerene dyads have not proven ideal for photovoltaic applications, it has been recently pointed out [183] that they can work as efficient active components in 

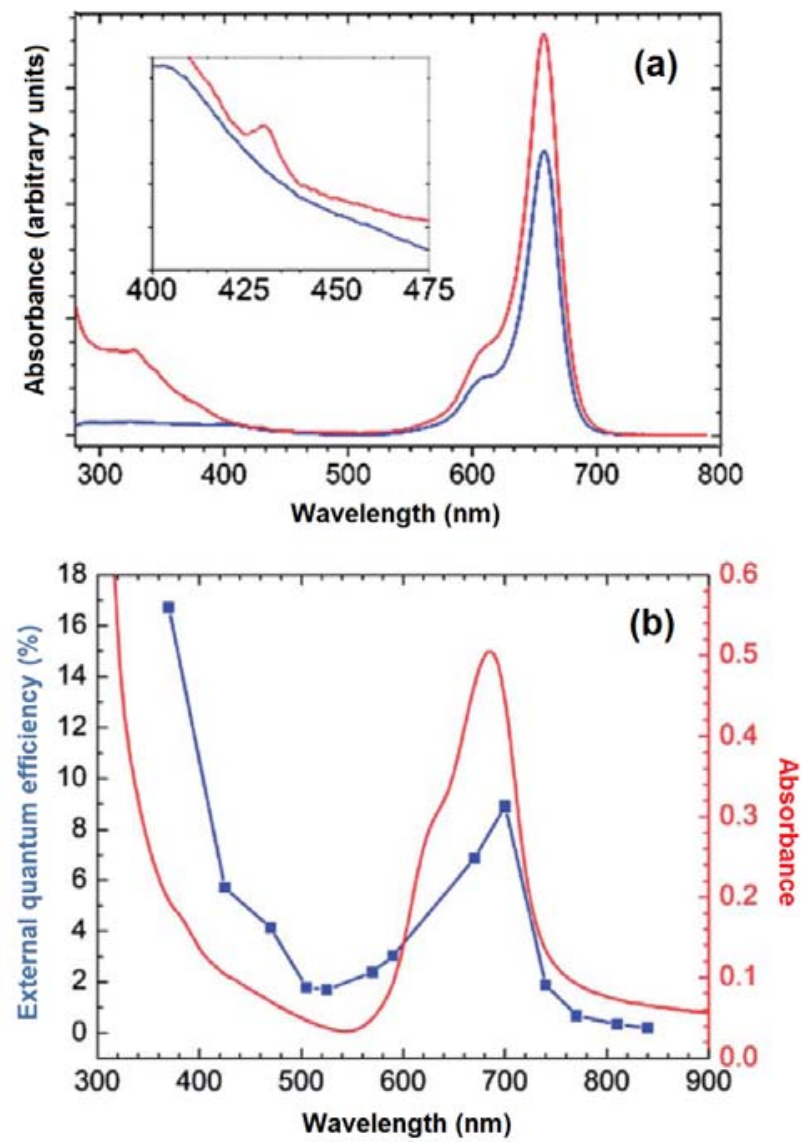

Fig. (8). (a) Absorption spectra of the azomethine ylide adduct (blue) and of the fulleropyrrolidine-squaraine dyad in chloroform (red). The inset highlights the peak at $430 \mathrm{~nm}$ characteristic of 1,2-monoadducts of $\mathrm{C}_{60}$. (b) Absorbance (red line) and external quantum efficiency (blue markers) of a photodetector consisting of a bilayer of the fulleropyrrolidine-squaraine dyad on top of a PEDOT:PSS layer, sandwitched between two electrodes with reverse applied bias voltage of $1 \mathrm{~V}$. During the measurements the device is illuminated, through the transparent ITO-on-glass electrode, with $0.5 \mathrm{~ms}$ ligh pulses with an intensity of $10 \mathrm{~mW} \mathrm{~cm}$ c $^{-2}$. Adapted from J. Mater. Chem. C 2014, 2, 1396-1399 with permission of The Royal Society of Chemistry.

photodetectors, where an external voltage bias is applied to favour charge transport and collection [211]. A simple vertical-device-geometry photodetector using a fulleropyrrolidine-squaraine blue dyad has been demonstrated. With an applied reverse voltage bias of $1 \mathrm{~V}$, the device exhibits approximately $10 \%$ external quantum efficiency (Fig. 8b), both in the red/near-IR portion of the spectrum, due to efficient photoinduced electron transfer from the excited state of the squaraine to the LUMO of the fulleropyrrolidine, and in the UV below $400 \mathrm{~nm}$ (where the donor does not absorb light, see Fig. 8a), thanks to the photoinduced hole transfer taking place from the fullerene derivative to the HOMO of the squaraine [183].

\section{E) SOLID-STATE CHEMISTRY AND CATALYTIC PROPERTIES}

Functionalization of fullerenes yields new species with modified chemical reactivity and usually different electrochemical and photochemical properties than the parent molecule. For example, most $\mathrm{C}_{60}$ derivatives display reduction potentials that are cathodically shifted (i.e., their reduction requires a greater negative potential) relative to pristine $\mathrm{C}_{60}$, except when strongly electronegative atoms or moieties are covalently bonded to the cage. Functionalized fullerenes are generally not able to undergo as many reversible reduction waves as pristine $\mathrm{C}_{60}$, with some of them incapable of reversible reduction (in general, the larger the number of covalent sideadducts, the larger the cathodic shift in reduction potentials, and the less likely the reversibility of the reduction waves). The presence of adducts covalently attached onto the carbon cage allows the employment of substitution chemistry techniques to produce further derivatives with different sidegroups. In this Section we review some of the solid-state chemistry applications that exploit the enhanced functionality of fullerene derivatives.

\section{E.1. Catalytic activity}

The monodisperse nano-sized molecular structure and the electron affinity of the pristine fullerenes are very desirable properties for catalytic applications. However, the lack of active sites on the fullerene cages prevents their direct use in catalysis: only few studies exist on pristine fullerenes, mainly on their use a component in composite catalysts $[212,213,214]$ or as sub-micron-size patterned crystalline catalyst supports [112]. Functionalization of fullerenes can introduce active sites for catalytic activity. For example, it has been recently shown that fullerol acts as an excellent hydrogen-bond catalyst in several organic reactions [215]. Hydrogen bond catalysis requires the catalysts to provide hydroxyl groups for hydrogen bonding with reactants, and fullerol is thus perfectly suited for this kind of applications. Fullerol displays high activity, $100 \%$ product selectivity and superb stability in Henry reactions [215]. Even more recently, ionic salts of the polar $\mathrm{C}_{60}(\mathrm{OH})_{8}$ fullerol derivative [21] have been shown to work as solid-state electrochemical catalysts for the hydrogen evolution reaction. The formal charges in theses salts are $\mathrm{Na}^{+}\left[\mathrm{C}_{60}(\mathrm{OH})_{8}\right]^{-}$and $\mathrm{K}^{+}\left[\mathrm{C}_{60}(\mathrm{OH})_{8}\right]^{-}$. The hydrogen evolution reaction occurs via a Volmer-Heyrosky mechanism, with the water molecules forming, prior to decomposition, a hydrogen bond with one or two hydroxyl groups of the fullerol moieties, while simultaneously bonding to the alkali counter-ion [216].

It is worth mentioning that a recent theoretical study [217] suggested that nitrogen-substitution of one or more carbon atoms of the pristine fullerene cage should result in azafullerenes with strong electrocatalytic properties for the water formation reaction, thanks to the partially reducing character of the $\mathrm{C}-\mathrm{N}$ (Pauling) sites. Nitrogen-substituted heterofullerenes are therefore of potential interest as cathode catalysts for hydrogen fuel cells.

E.2. Fullerene derivatives as chemically amplified electron-beam resists 
$\mathrm{C}_{60}$ films are known to work as high-resolution negative electron beam resists with high dry-etch durability; however, $\mathrm{C}_{60}$ films cannot be prepared by spin-coating because of the low viscosity of the $\mathrm{C}_{60}$ solutions, and the sensitivity of the resist is not very high [218]. Molecular and polymeric fullerene derivatives have been proposed for chemicallyamplified electron-beam resist applications [219,220]. Fullerene derivatives containing polyethyleneglycol side chains exhibit high sensitivity and resolution, good lower line width roughness, and excellent etch durability [221]. However, halogenated solvents are required for the spincasting and development of these resists, and such solvents are not acceptable (safe) for commercial use. This problem was recently solved by using phenol-based fullerene derivatives [222], which are compatible with industryapproved casting solvents and developers.

\section{E.3. Electrochemical devices employing fullerene derivatives}

Carbonaceous materials such as graphite have been widely used as anodes in commercial Li-ion batteries for several years [223]. Early studies on $\mathrm{C}_{60}$ and $\mathrm{C}_{70}$ electrodes to investigate their possible implementation in electrochemical cells showed however poor reversibility of lithium intercalation [224]. More recent studies on (poly)crystalline lithium fullerides have demonstrated the possibility of intercalating up to $28 \mathrm{Li}$ atoms per $\mathrm{C}_{60}$ molecules, with the formation of Li clusters in the interstitial sites [225]. Such high concentration is clearly not compatible with total ionization and charge transfer from lithium to the $\mathrm{C}_{60}$ units, as these can accommodate only up to 6 electrons in their LUMO-derived level, so that partial covalency and hybridization of electronic levels have been suggested [226]. Partial charge transfer of only three electrons per $\mathrm{C}_{60}$ unit has been reported [126] in the lowest-stoichiometry stable crystalline compound, of chemical formula $\mathrm{Li}_{4} \mathrm{C}_{60}$ [136]. A similar maximum charge transfer was found in $\mathrm{Li}_{12} \mathrm{C}_{60}$, whose nominal charge state was reported to be $\mathrm{Li}_{8}\left(\mathrm{Li}^{+}\right)_{4} \mathrm{C}_{60}{ }^{4-}$ [156]. These findings entail that lithium in excess of 3 or 4 atoms per $\mathrm{C}_{60}$ is present as neutral $\mathrm{Li}$ and as such does not contribute to the charge storage. As a consequence, despite the relatively high room-temperature mobility reported e.g. in the $\mathrm{Li}_{4} \mathrm{C}_{60}$ compound [136], commercial application of pristine fullerenes in $\mathrm{Li}$-ion batteries is not viable due to poor electrochemical reversibility and low ion density.

Fullerene derivatives have been probed in search for more suitable materials for Li-ion electrochemical applications. Higher Li-storage capacities and electrochemical stabilities were observed in hydrogenated fullerenes (fulleranes) with compositions $\mathrm{C}_{60} \mathrm{H}_{n}$ with $n$ up to 60 and $\mathrm{C}_{70} \mathrm{H}_{n}$ with $n$ up to 70. In these systems the lithium intercalation capacity was found to be dependent on the degree of hydrogenation, suggesting that $\mathrm{Li}$ stockage occurs via $\mathrm{Li}-\mathrm{H}$ bonding rather than as interstitial clustering. The storage capacity was however only partially reversible [156].
More recently an oxidized fullerene derivative, of chemical formula $\mathrm{C}_{60} \mathrm{O}_{10}$, has been investigated as storage material for Li-ion battery applications [227]. This material was obtained by pyrolysis of a molecular salt with silver (chemical formula $\mathrm{Ag}_{4} \mathrm{C}_{60} \mathrm{O}_{9}(\mathrm{OH})_{12}$ ), which yielded $\mathrm{C}_{60} \mathrm{O}_{10}$ intermixed with $\mathrm{Ag}$ nanoparticles. In galvanostatic chargedischarge experiments using a fullerene-coated copper electrode and a lithium-metal reference electrode, both the pure $\mathrm{C}_{60} \mathrm{O}_{10}$ derivative and its nanocomposite with metallic silver showed relatively high discharge capacity, with reasonable stability over fifty charge-discharge cycles. Cyclic voltammetry on the $\mathrm{C}_{60} \mathrm{O}_{10} / \mathrm{Ag}$ nanocomposite sample revealed a cathodic peak at $0.37 \mathrm{~V}$, ascribed to the formation of a $\mathrm{Li}_{n}\left(\mathrm{C}_{60} \mathrm{O}_{10}\right)$ salt, and two anodic peaks at 0.82 and 1.35 $\mathrm{V}$ that are assigned to the liberation of $\mathrm{Li}^{+}$from such salt [227]. The observation of reversible redox reactions between $\mathrm{C}_{60} \mathrm{O}_{10}$ and $\mathrm{Li}^{+}$indicates that this oxidized fullerene derivative might be interesting as anode material or modifier for $\mathrm{Li}$-ion batteries.

The $\mathrm{C}_{60} \mathrm{H}_{n}$ fullerane derivatives have been investigated also for hydrogen storage applications. Fulleranes of varying stoichiometries can be obtained via different methods: bombardment with atomic hydrogen [228], Birch reduction [229], zinc acid reduction [230], hydrogen atom transfer from 9,10-dihydroanthracene [231], or direct solid phase hydrogenation at elevated temperatures and pressures for extended periods of time $\left(>400{ }^{\circ} \mathrm{C}\right.$ and $>100$ bar of $\left.\mathrm{H}_{2}\right)$ [232]. Dehydrogenation by annealing the pure $\mathrm{C}_{60}$ fulleranes material to extract back molecular $\mathrm{H}_{2}$ gas is not commercially viable: a major drawback of fulleranes as hydrogen storage materials is the high temperature $\left(>500^{\circ} \mathrm{C}\right)$ required for hydrogen desorption, which is due to the molecular stability enhancement with increasing degree of hydrogenation. The strong binding of the hydrogen adducts also causes partial decomposition of the carbon cage upon dehydrogenation, so that the desorption of hydrogen from fulleranes is accompanied by release of hydrocarbons and formation of polycyclic aromatic hydrocarbons $[233,234,235]$. Some studies have shown that hydrogenation/dehydrogenation processes can be achieved for $\mathrm{C}_{60}$ dissolved in organic solvents (such as toluene) [229]; however, in most cases hydrogenation was irreversible, or dehydrogenation incomplete [236,237,238].

On the other hand, it has been recently shown [239] that a alkali-organic fullerene derivative, of average chemical formula $\mathrm{Li}_{x} \mathrm{C}_{60} \mathrm{H}_{y}$ with $x$ close to 6 , can be used as active material for reversible hydrogen storage. The material, which displays an average charge transfer of six electrons to the $\mathrm{C}_{60}$ cages and the spectral signature of partial selfpolymerization (possibly related to the presence of a minority polymeric $\mathrm{Li}_{4} \mathrm{C}_{60}$ phase $\left.[126,136]\right)$, is able to undergo reversible hydrogenation to $\mathrm{Li}_{6} \mathrm{C}_{60} \mathrm{H}_{40}$, withy $=40$ covalently linked hydrogens. Hydrogen storage is achieved by heating the $\mathrm{Li}_{\mathrm{x}} \mathrm{C}_{60}$ material to between 200 and $350{ }^{\circ} \mathrm{C}$ under an applied $\mathrm{H}_{2}$ pressure between 25 and 100 bars. Hydrogen storage of $5 \%$ in weight is achieved by applying 
105 bars of $\mathrm{H}_{2}$ pressure to $\mathrm{Li}_{6} \mathrm{C}_{60}$ kept between 300 and 350 ${ }^{\circ} \mathrm{C}$, and the hydrogen release shows an onset at $270{ }^{\circ} \mathrm{C}$ in thermogravimetry-residual gas analysis experiments [239].

Considering the catalytic activity, proton conduction properties and potentially high storage density of some fullerene derivatives, the possible implementation of functionalized $\mathrm{C}_{60}$ in fuel cells should be further investigated in future experimental studies.

\section{CONFLICT OF INTEREST}

The authors confirm that this article content has no conflict of interest.

\section{ACKNOWLEDGEMENTS}

The authors acknowledge support from the Spanish Ministry of Science and Innovation, through project FIS2011-24439, and from the Generalitat de Catalunya, under project 2014 SGR-581.

\section{REFERENCES}

[1] Mchedlov-Petrossyan, N.O. Fullerenes in liquid media: An unsettling intrusion into the solution chemistry. Chem. Rev., 2013, 113, 5149-5193.

[2] Fortner, J.D.; Lyon, D.Y.; Sayes, C.M.; Boyd, A.M.; Falkner, J.C.; Hotze, E.M.; Alemany, L.B.; Tao, Y.J.; Guo, W.; Ausman, K.D.; Colvin, V.L.; Hughes, J.B. $\mathrm{C}_{60}$ in water: Nanocrystal formation and microbial response. Environ Sci Technol., 2005, 39, 4307-4316.

[3] Hamed, A.; Sun, Y.Y.; Tao, Y.K.; Meng, R.L.; Hor, P.H. Effects of oxygen and illumination on the in situ conductivity of $\mathrm{C}_{60}$ thin films. Phys. Rev. B, 1993, 47, 10873.

[4] Katz, E.A.; Faiman, D.; Mishori, B.; Shapira, Y.; Shames, A.I.; Shtutina, S.; Goren, S. Changes in the photoelectrical properties and generation of photoinduced defects under light/air exposure of $\mathrm{C}_{60}$ thin films. J. Appl. Phys., 1998, 84, 3333-3337.

[5] Echegoyen, L.; Diederich, F.; Echegoyen, L.E. Electrochemistry of fullerenes. In: Fullerenes: Chemistry, Physics, and Technology; Ruoff, R.S., Eds.; John Wiley \& Sons, Inc.: New York, 2000; pp. 1-51.

[6] Macovez, R.; Goldoni, A.; Petaccia, L.; Marenne,I.; Brühwiler, P.A.; Rudolf, P. Reversible phase transformation and doubly charged anions at the surface of simple cubic $\mathrm{RbC}_{60}$. Phys. Rev. Lett., 2008, 101, 236403.

[7] Bracher, P.J.; Schuster, D.I. Electron Transfer in Functionalized Fullerenes. In: Developments in Fullerene Science: Fullerenes: From Synthesis to Optoelectronic Properties. Guldi, D.M.; Martin, N., Eds.; Springer, 2002; Vol. 4, pp. 163-212.

[8] Kroto, H.W.; Heath, J.R.; O’Brien, S.C.; Curl, R.F.; Smalley, R.E. $\mathrm{C}_{60}$ : Buckminsterfullerene. Nature, 1985, 318, 162.

[9] Krätschmer, W.; Lamb, L.D.; Fostiropoulos, K.; Huffman, D.R. Solid $\mathrm{C}_{60}$ : A new form of carbon. Nature, 1990, 347, 354 .
[10] Assink, R.A.; Schirber, J.E.; Loy, D.A.; Morosin, B.; Carlson, G.A. Intercalation of molecular species into the interstitial sites of fullerene. J. Mat. Res., 1992, 7, 21362143.

[11] Anthopoulos, T.D.; Kooistra, F.B.; Wondergem, H.J.; Kronholm, D.; Hummelen, J.C.; de Leeuw, D.M. Air-stable n-channel organic transistors based on a soluble $\mathrm{C}_{84}$ fullerene derivative. Adv. Mater., 2006, 18, 1679-1684.

[12] Ball, J.M.; Bouwer, R.K.M.; Kooistra, F.B.; Frost, J.M.; Qi, Y.; Domingo, E.B.; Smith, J.; de Leeuw, D.M.;

Hummelen, J.C.; Nelson, J.; Kahn, A.; Stingelin, N. Bradley, D.D.C.; Anthopoulos, T.D. Soluble fullerene derivatives:

The effect of electronic structure on transistor performance and air stability. J. Appl. Phys., 2011, 110, 014506.

[13] Labille, J; Masion, A.; Ziarelli, F.; Rose, J.; Brant, J.; Villiéras, F.; Pelletier, M.; Borschneck, D.; Wiesner, M.R.; Bottero, J.-Y. Hydration and dispersion of $\mathrm{C}_{60}$ in aqueous systems: the nature of water-fullerene interactions. Langmuir, 2009, 25, 11232-11235.

[14] Da Ros, T.; Prato, M. Medicinal chemistry with fullerenes and fullerene derivatives. Chem. Commun., 1999, $8,663-669$.

[15] Guldi, D.M.; Hungerbuehler, H.; Asmus, K.-D. Unusual redox behavior of a water soluble malonic acid derivative of $\mathrm{C}_{60}$ : evidence for possible cluster formation. J. Phys. Chem., 1995, 99, 13 487-13493.

[16] Guldi, D.M. Electron transfer to buckminster-fullerenes and functionalized fullerene derivatives in aqueous and protic media, as studied by radiolytic techniques. Res. Chem. Intermed., 1997, 23, 653-673.

[17] Brettreich, M.; Hirsch, A. A highly water-soluble dendro[60]fullerene. Tetrahedron Lett., 1998, 39, 27312734.

[18] Tabata, Y.; Murakami, Y.; Ikada, Y. Antitumor effect of poly(ethylene glycol)-modified fullerene. Fullerene Sci. Technol., 1997, 5, 989-100.

[19] Chiang, L.Y.; Wang, L.-Y.; Swirczewski, J.W.; Soled, S.; Cameron, S. Efficient synthesis of polyhydroxylated fullerene derivatives via hydrolysis of polycyclosulfated precursors. J. Org. Chem., 1994, 59, 3960-3968.

[20] Liu, Y.; Zhang, G.; Niu, L.; Gan, L.; Liang, D. Assembly of Janus fullerenol: a novel approach to prepare rich carbon structures. J. Mater. Chem., 2011, 21, 14864 14868

[21] Zhang, G.; Liu, Y.; Liang, D.; Gan, L.; Li, Y. Facile synthesis of isomerically pure fullerenols and formation of spherical aggregates from $\mathrm{C}_{60}(\mathrm{OH})_{8}$. Angew. Chem. Int. Ed., 2010, 49, 5293-5295.

[22] Wang, S.; He, P.; Zhang, J.-M.; Jiang, H.; Zhu, S.-Z. Novel and efficient synthesis of water-soluble [60]fullerenol by solvent-free reaction. Synth. Commun., 2005, 35, 18031807.

[23] Li, J.; Takeuchi, A.; Ozawa, M.; Li, X.; Saigo, K.; Kitazawa, K. $\mathrm{C}_{60}$ fullerol formation catalysed by quaternary ammonium hydroxides. J. Chem. Soc. Chem. Commun., 1993, 23, 1784-1785. 
[24] Kokubo, K.; Matsubayashi, K.; Tategaki, H.; Takada, H.; Oshima, T. Facile synthesis of highly water-soluble fullerenes more than half-covered by hydroxyl groups. ACS Nano, 2008, 2, 327-333.

[25] Zachariah, M.; Mitsari, E.; Romanini, M.; Zygouri, P.; Gournis, D.; Barrio, M.D.; Tamarit, J.L1.; Macovez, R.

Water-triggered conduction mediated by proton exchange in a hygroscopic fulleride and its hydrate. J. Phys. Chem. C, 2015, 119, 685-694.

[26] Nakanishi, T.; Michinobu, T.; Yoshida, K.; Shirahata, N.; Ariga, K.; Möhwald, H.; Kurth, D.G. Nanocarbon superhydrophobic surfaces created from fullerene-based hierarchical supramolecular assemblies. Adv. Mater., 2008, 20, 443-446

[27] Stinchombe, J.; Penicaud, A.; Bhyrappa, P.; Boyd, P.D.W.; Reed, C.A. Buckminsterfulleride(1-) salts: synthesis, EPR, and the Jahn-Teller distortion of $\mathrm{C}_{60} 0^{-} . \mathrm{J} . \mathrm{Am}$. Chem. Soc., 1993, 115, 5212-5217.

[28] Schell-Sorokin, A.J.; Mehran, F.; Eaton, G.R.; Eaton, S.S.; Viehbeck, A.; O’Toole, T.R.; Brown, C.A. Electron spin relaxation times of $\mathrm{C}_{60}{ }^{-}$in solution. Chem. Phys. Lett., 1992, 195, 225-232.

[29] Mirkin, C.A.; Caldwell, W.B. Thin film, fullerene-based materials. Tetrahedron, 1996, 52, 5113-5130.

[30] Maliszewskyj, N.C.; Heiney, P.A.; Jones, D.R.; Strongin, R.M.; Cichy, M.A.; Smith III, A.B. Langmuir films of fullerene $\mathrm{C}_{60}$, fullerene epoxide $\mathrm{C}_{60} \mathrm{O}$ and dihydrofulleroid $\mathrm{C}_{61} \mathrm{H}_{2}$. Langmuir, 1993, 9, 1439-1441.

[31] Mishina, E.D.; Misuryaev, T.V.; Nikulin, A.A.; Novak, V.R.; Rasing, Th.; Aktsipetrov, O.A. Hyper-Rayleigh scattering from Langmuir films of $\mathrm{C}_{60}$ and its derivatives. $J$. Opt. Soc. Am., 1999, B16, 1692-1696.

[32] Taylor, R.; Walton, D.R.M. The chemistry of fullerenes. Nature, 1993, 363,685-693.

[33] Wilson, S.R.; Schuster, D.I.; Nuber, B.; Meier, M.S.; Maggini, M.; Prato, M.; Taylor, R. Organic chemistry of fullerenes. In: Fullerenes: Chemistry, Physics, and Technology; Ruoff, R.S., Eds.; John Wiley \& Sons, Inc.: New York, 2000; pp. 91-176.

[34] Diederich, F.; Kessinger, R. Templated regioselective and stereoselective synthesis in fullerene chemistry. Acc. Chem. Res., 1999, 32, 537-545.

[35] Tajima, Y.; Takeshi, K.; Shigemitsu, Y.; Numata, Y. Chemistry of fullerene epoxides: Synthesis, structure, and nucleophilic substitution-addition reactivity. Molecules, 2012, 17, 6395-6414.

[36] Jousselme, B.; Blanchard, P.; Levillain, E.; de Bettignies, R.; Roncali, J. Electrochemical synthesis of $\mathrm{c}_{60^{-}}$ derivatized

poly(thiophene)s from tailored precursors. Macromolecules, 2003, 36, 3020-3025.

[37] Ramos, A.M.; Rispens, M.T.; van Duren, J.K.J.; Hummelen, J.C.; Janssen, R.A.J. Photoinduced electron transfer and photovoltaic devices of a conjugated polymer with pendant fullerenes. J. Am. Chem. Soc., 2001, 123, 6714-6715.
[38] Chuard, T.; Deschenaux, R. Design, mesomorphic properties, and supramolecular organization of [60]fullerenecontaining thermotropic liquid crystals. J. Mater. Chem., 2002, 12, 1944-1951.

[39] Lu, S.; Jin, T.; Bao, M.; Yamamoto, Y. Cobaltcatalyzed hydroalkylation of [60]fullerene with active alkyl bromides: selective synthesis of monoalkylated fullerenes. $J$. Am. Chem. Soc., 2001, 133, 12842-12848.

[40] Vostrowsky, O.; Hirsch, A. Heterofullerenes. Chem. Rev., 2006, 106, 5191-5207.

[41] Dunk, P. W.; Rodríguez-Fortea, A.; Kaiser, N. K.; Shinohara, H.; Poblet, J. M.; Kroto, H. W. Formation of heterofullerenes by direct exposure of $\mathrm{C}_{60}$ to boron vapor. Angew. Chem. Int. Ed., 2013, 52, 315-319

[42] Iwamatsu,S.; Stanisky, C.M.; Cross,R.J.; Saunders, M.; Mizorogi, N.; Nagase, S.; Murata, S. Carbon monoxide inside an open-cage fullerene. Angew. Chem. Int. Ed., 2006, 45, 5337-5340.

[43] Nasibulin, A.G.; Pikhitsa, P.V.; Jiang, H.; Brown, D.P.; Krasheninnikov, A.V.; Anisimov, A.S.; Queipo, P.; Moisala, A.; Gonzalez, D.; Lientschnig, G.; Hassanien, A.; Shandakov, S.D.; Lolli, G.; Resasco, D.E.; Choi, M.; Tománek, D.; Kauppinen, E.I. A novel hybrid carbon material. Nat. Nanotech., 2007, 2, 156-161.

[44] Vougioukalakis, G.C.; Roubelakis, M.M.; Orfanopoulos, M. Open-cage fullerenes: towards the construction of nanosized molecular containers. Chem. Soc. Rev., 2010, 39, 817-844.

[45] Shi, L.; Yang, D.; Colombo, F.; Yu, Y.; Zhang, W.-X.; Gan, L. Punching a carbon atom of $\mathrm{C}_{60}$ into its own cavity to form an endohedral complex $\mathrm{CO} @ \mathrm{C}_{59} \mathrm{O}_{6}$ under mild conditions. Chem. Eur. J., 2013, 19, 16545-16549.

[46] Xiao, Z.; Ye, G.; Liu, Y.; Chen, S.; Peng, Q.; Zuo, Q.; Ding, L. Pushing fullerene absorption into the near-IR region by conjugately fusing oligothiophenes. Angew. Chem. Int. Ed., 2012, 51, 9038-9041.

[47] Neretin, I.S.; Slovokhotov, Y.L. Chemical crystallography of fullerenes. Russ. Chem. Rev., 2004, 73, 455.

[48] Smith, B.W.; Monthio, M.; Luzzi, D.E. Encapsulated $\mathrm{C}_{60}$ in carbon nanotubes. Nature, 1998, 396, 323-324.

[49] Stepanian, S.G.; Karachevtsev, V.A.; Plokhotnichenko, A.M.; Adamowicz, L.; Rao, A.M. IR spectra of photopolymerized $\mathrm{C}_{60}$ films. Experimental and density functional theory study. J. Phys. Chem. B, 2006, 110, 15769 -15775 .

[50] Rao, A.M.; Zhou, P.; Wang, K.-A.; Hager, G.T.; Holden, J.M.; Wang, Y.; Lee, W.T. ; Bi, X.X.; Eklund, P.C.; Cornett, D.S.; Duncan, M.A.; Amster, I.J. Photoinduced polymerization of solid $\mathrm{C}_{60}$ films. Science, 1993, 259, 955957.

[51] Hassanien, A.; Gasperic, J.; Demsar, J.; Musevic, I.; Mihailovic, D. Atomic force microscope study of photopolymerized and photo-dimerized epitaxial $\mathrm{C}_{60}$ films. Appl. Phys. Lett., 1997, 70, 417. 
[52] Núñez-Regueiro, M.; Marques, L.; Hodeau, J -L.; Béthoux, O.; Perroux, M. Polymerized fullerite structures. Phys. Rev. Lett., 1995, 74, 278.

[53] Riccò, M.; Shiroka, T.; Belli, M.; Pontiroli, D.; Pagliari, M.; Ruani, G.; Palles, D.; Margadonna, S.; Tomaselli, M. Unusual polymerization in the $\mathrm{Li}_{4} \mathrm{C}_{60}$ fulleride. Phys. Rev. $B$ 2005, 72, 155437

[54] Pontiroli, D.; Aramini, M.; Gaboardi, M.; Mazzani, M.; Gorreri, A.; Riccò, M.; Margiolaki, I.; Sheptyakov, D. Ionic conductivity in the $\mathrm{Mg}$ intercalated fullerene polymer $\mathrm{Mg}_{2} \mathrm{C}_{60}$. Carbon, 2013, 51, 143-147.

[55] Macovez, R.; Rudolf, P.; Marenne, I.; Kjeldgaard, L.; Brühwiler, P.A.; Pichler, T.; Vilmercati, P.; Larciprete, R.; Petaccia, L.; Bertoni, G.; Goldoni, A. Electronic surface reconstruction and correlation in the fcc and dimer phases of $\mathrm{RbC}_{60}$. Phys. Rev. B, 2007, 75, 195424.

[56] Wang, G.-W.; Komatsu, K.; Murata, Y.; Shiro, M. Synthesis and X-ray structure of dumb-bell-shaped $\mathrm{C}_{120}$. Nature, 1997, 387, 583-586.

[57] Stephens, P.W.; Bortel, G.; Faigel, G.; Tegze, M.; Janossy, A.; Peckker, S.; Oszlanyi, G.; Forró, L. Polymeric fullerene chains in $\mathrm{RbC}_{60}$ and $\mathrm{KC}_{60}$. Nature, 1994, 370, 636639.

[58] Macovez, R.; Schiessling, J.; Castellarin-Cudia, C.; Vilmercati, P.; Petaccia, L.; Bertoni, G.; Goldoni, A.; Rudolf, P. Metal-to-insulator transition in thin-film polymeric $\mathrm{AC}_{60}$. New J. Phys., 2009, 11, 023035.

[59] Oszlanyi, G.; Baumgartner, G.; Faigel, G.; Forró, L. $\mathrm{Na}_{4} \mathrm{C}_{60}$ : An alkali intercalated two-dimensional polymer. Phys. Rev. Lett., 1997, 78, 4438.

[60] Margadonna, S.; Pontiroli, D.; Belli, M.; Shiroka, T.; Riccò, M.; Brunelli, M. $\mathrm{Li}_{4} \mathrm{C}_{60}$ : A polymeric fulleride with a two-dimensional architecture and mixed interfullerene bonding motifs. J. Am. Chem. Soc., 2004, 126, 15032. [61] Heiney, P.A.; Fischer, J. E.; McGhie, A.R.; Romanow, W.J.; Denenstein, A.M.; Jr. McCauley, J.P.; Smith, A.B.; Cox, D.E. Orientational ordering transition in solid $\mathrm{C}_{60}$. Phys. Rev. Lett., 1991, 66, 2911.

[62] Lee, H.M.; Olmstead, M. M.; Suetsuna, T.; Shimotani, H.; Dragoe, N.; Cross, R.J.; Kitazawa, K.; Balch, A. L.

Crystallographic characterization of $\mathrm{Kr} @ \mathrm{C}_{60}$ in $\left(0.09 \mathrm{Kr} @ \mathrm{C}_{60} / 0.91 \mathrm{C}_{60}\right) \cdot\left\{\mathrm{Ni}{ }^{\mathrm{II}}(\mathrm{OEP})\right\} \cdot 2 \mathrm{C}_{6} \mathrm{H}_{6}$. Chem

Commun., 2002, 13, 1352-1353.

[63] Stanciu, C.; Ehlich, R.; Hertel, I.V.

Photopolymerization of $\mathrm{C}_{60}$ and $\mathrm{Li} @ \mathrm{C}_{60}$ studied by secondharmonic generation and infrared spectroscopy. Appl. Phys. A, 2004, 79, 515.

[64] Kessler, B.; Bringer, A.; Cramm, S.; Schlebusch, C.; Eberhardt, W.; Suzuki, S.; Achiba, Y.; Esch, F.; Barnaba, M.; Cocco, D. Evidence for Incomplete Charge Transfer and La-Derived States in the Valence Bands of Endohedrally DopedLa@C $\mathrm{C}_{82}$. Phys. Rev. Lett., 1997, 79, 2289. [65] Vaughan, G.B.M.; Heiney, P.A.; Cox, D.E.; McGhie, A.R.; Jones, D.R.; Strongin, R.M.; Cichy, M.A.; Smith III, A.B. The orientational phase transition in solid buckminsterfullerene epoxide $\left(\mathrm{C}_{60} \mathrm{O}\right)$. Chem. Phys., 1992, 168, 185-193.
[66] Stetzer, M.R.; Heiney, P.A.; Stephens, P.W.; Dinnebier, R. E.; Zhu, Q.; McGhie, A.R.; Strongin, R.M.; Brandt, B.M.; Smith III, A.B. Structure and phase transitions of the 6,6-cyclopropane isomer of $\mathrm{C}_{61} \mathrm{H}_{2}$. Phys. Rev. B, 2000, 62, 9305.

[67] Lommen, A.N.; Heiney, P.A.; Vaughan, G.B.M.; Stephens, P.W.; Liu, D.; Li, D.; Smith, A.L.; McGhie, A.R.; Strongin, R.M.; Brard, L.; Smith III, A.B. Structure and phase transition of the 6,5 -annulene isomer of $\mathrm{C}_{61} \mathrm{H}_{2}$. Phys. Rev. B, 1994, 49, 12572 .

[68] Meingast, C.; Roth, G.; Pintschovius, L.; Michel, R.H.; Stoermer, C.; Kappes, M.M.; Heiney, P.A.; Brard, L.; Strongin, R.M.; Smith III, A.B. Structure, dynamics, and phase transitions in the fullerene derivatives $\mathrm{C}_{60} \mathrm{O}$ and $\mathrm{C}_{61} \mathrm{H}_{2}$. Phys. Rev. B, 1996, 54, 124.

[69] Troshin, P.A.; Kemnitz, E.; Troyanov, S.I.

Characterization of reactions of fullerene $\mathrm{C}_{60}$ with bromine. Crystal structures of bromofullerenes $\mathrm{C}_{60} \mathrm{Br}_{6}$, $\mathrm{C}_{60} \mathrm{Br}_{6} \cdot \mathrm{CS}_{2}, \mathrm{C}_{60} \mathrm{Br}_{8} \cdot \mathrm{CHBr}_{3} \cdot 2 \mathrm{Br}_{2}$, and $\mathrm{C}_{60} \mathrm{Br}_{24} \cdot \mathrm{C}_{6} \mathrm{H}_{4} \mathrm{Cl}_{2} \cdot \mathrm{Br}_{2}$. Russ. Chem. B+, 2004, 53, 2787-2792.

[70] Hall, L.E.; McKenzie, D.R.; Attalla, M.I.; Vassallo, A.M.; Davis, R.L.; Dunlop, J.B.; Cockayne, D.J. The structure of hydrogenated fullerene $\left(\mathrm{C}_{60} \mathrm{H}_{36}\right)$. J. Phys. Chem., 1993, 97, 5741-5744.

[71] Rispens, M.T.; Meetsma, A.; Rittberger, R.; Brabec, C.J.; Sariciftci, N.S.; Hummelen, J.C. Influence of the solvent on the crystal structure of PCBM and the efficiency of MDMO-PPV: PCBM 'plastic' solar cells. Chem. Commun., 2003, 17, 2116-2118

[72] Colle, R.; Grosso, G.; Ronzanic, A.; Massimo Gazzano, M.; Palermo, V. Anisotropic molecular packing of soluble $\mathrm{C}_{60}$ fullerenes in hexagonal nanocrystals obtained by solvent vapor annealing. Carbon, 2012, 50, 1332-1337

[73] Yang, X.N.; van Duren, J.K.J.; Rispens, M.T.; Hummelen, J.C.; Janssen, R.A.J.; Michels, M.A.J.; Loos, J. Crystalline organization of a methanofullerene as used for plastic solar-cell applications. Adv. Mater., 2004, 16, 802806

[74] Nakanishi, T.; Ariga, K.; Michinobu, T.; Yoshida, K.; Takahashi, H.; Teranishi, T.; Möhwald, H.; Kurth, D.G. Small, 2007, 3, 2019-2023

[75] Brown, C.M.; Cristofolini, L.; Kordatos, K.; Prassides, K.; Bellavia, C.; González, R.; Keshavarz-K., M.; Wudl, F.; Cheetham, A.K.; Zhang, J.P.; Andreoni, W.; Curioni, A.; Fitch, A.N.; Pattison, P. On the Crystal Structure of Azafullerene $\left(\mathrm{C}_{59} \mathrm{~N}\right)_{2}$. Chem. Mater., 1996, 8, 2548-2550. [76] Nakanishi, T. Supramolecular soft and hard materials based on self-assembly algorithms of alkyl-conjugated fullerenes. Chem. Commun., 2010, 46, 3425-3436 [77] Babu, S.S.; Möhwald, H.; Nakanishi, T. Recent progress in morphology control of supramolecular fullerene assemblies and its applications. Chem. Soc. Rev., 2010, 39, 4021-4035.

[78] Sawamura, M.; Kawai, K.; Matsuo, Y.; Kanie, K.; Kato, T.; Nakamura, E. Stacking of conical molecules with a fullerene apex into polar columns in crystals and liquid crystals. Nature, 2002, 419, 702-705. 
[79] Campidelli, S.; Bourgun, P.; Guintchin, B.; Furrer, J.; Stoeckli-Evans, H.; Saez, I.M.; Goodby, J.W.; Deschenaux, R. Diastereoisomerically pure fulleropyrrolidines as chiral platforms for the design of optically active liquid crystals. $J$. Am. Chem. Soc., 2010, 132, 3574.

[80] Mamlouk, H.; Heinrich, B;. Bourgogne, C.; Donnio, B.; Guillon, D.; Felder-Flesch, D. A nematic [60]fullerene supermolecule: when polyaddition leads to supramolecular self-organization at room temperature. J. Mater. Chem., 2007, 17, 2199-2205.

[81] Zhang, X.; Nakanishi, T.; Ogawa, T.; Saeki, A.; Seki, S.; Shen, Y.; Yamauchi, Y.; Takeuchi, M. Flowerlike supramolecular architectures assembled from $\mathrm{C}_{60}$ equipped with a pyridine substituent. Chem. Commun., 2010, 46, 8752-8754.

[82] Konarev, D.V.; Lyubovskaya, R.N. Donor-acceptor complexes and radical ionic salts based on fullerenes. Russ. Chem. Rev., 1999, 68, 19-38.

[83] Céolin, R.; Tamarit, J.L1.; Barrio, M.; López, D.O.; Toscani, S.; Allouchi, H.; Agafonov, V.; Szwarc, H. Solidstate studies on a cubic 1:1 solvate of $\mathrm{C}_{60}$ grown from dichloromethane and leading to another hexagonal $\mathrm{C}_{60}$ polymorph. Chem. Mater., 2001, 13, 1349-1355

[84] Michaud, F.; Barrio, M.; López, D.O.; Tamarit, J.L1.; Agafonov, V.; Toscani, S.; Szwarc, H.; Céolin, R. Solidstate studies on a $\mathrm{C}_{60}$ solvate grown from 1,1,2trichloroethane. Chem. Mater., 2000, 12, 3595-3602. [85] Michaud, F.; Barrio, M.; Toscani, S.; López, D.O.; Tamarit, J.LI.; Agafonov, V.; Szwarc, H.; Céolin, R. Solidstate studies on single and decagonal crystals of $\mathrm{C}_{60}$ grown from 1,2-dichloroethane. Phys. Rev. B, 1998, 57, 1035110358.

[86] Fleming, R.M.; Rosseinsky, M.J; Ramirez, A.P.; Murphy, D.W.; Tully, J.C.; Haddon, R.C.; Siegrist, T.; Tycko, R.; Glarum, S.H.; Marsh, P.; Dabbagh, G.; Zahurak, S.M.; Makhija, A.V.; Hampton, C. Preparation and structure of the alkali-metal fulleride $\mathrm{A}_{4} \mathrm{C}_{60}$. Nature, 1991, 352, 701703.

[87] Zhu, Q.; Zhou, O.; Fischer, J.E.; McGhie, A.R.; Romanow, W.J.; Strongin, R.M.; Cichy, M.A.; Smith III, A.B. Unusual thermal stability of a site-ordered $\mathrm{MC}_{60}$ rocksalt structure $(\mathrm{M}=\mathrm{K}, \mathrm{Rb}$, or $\mathrm{Cs})$. Phys. Rev. B, 1993, 47, 13948.

[88] Pekke, S.; Kováts, E.; Oszlányi, G.; Bényei, G.; Klupp, G.; Bortel, G.; Jalsovszky, I.; Jakab, E.; Borondics, F.; Kamarás, K.; Bokor, M.; Kriza, G.; Tompa, K.; Faigel, G. Rotor-stator molecular crystals of fullerenes with cubane. Nat. Mater., 2005, 4, 764-767.

[89] Ramm, M.; Luger, P.; Zobel, D.; Duczek, W.; Boeyens, J.C.A. Static disorder in hexagonal crystal structures of $\mathrm{C}_{60}$ at $100 \mathrm{~K}$ and $20 \mathrm{~K}$. Cryst. Res. Technol., 1996, 31, 43-53. [90] Avramenko, N.V.; Mirakyan, A.V.; Neretin, I.S.; Slovokhotov, Yu.L.; Korobov, M.V. Thermodynamic properties of the binary system $\mathrm{C}_{60}-1,3,5$-trimethylbenzene. Thermochim Acta, 2000, 344, 23-28.
[91] Oszlanyi, G.; Bortel, G.; Faigel, G.; Pekker, S.; Tegze, M. Dynamic origin of the orthorhombic symmetry of $\mathrm{C}_{60}$-npentane. Solid State Commun., 1994, 89, 417-419.

[92] Dyachenko, O.A.; Graja, A. Crystal structure of $\mathrm{C}_{60}$ and $\mathrm{C}_{70}$ compounds. Fullerene Sci. Techn., 1999, 7, 317-385.

[93] Jansen, M.; Waidmann, G. Darstellung und

Charakterisierung der Fulleren-Kokristallisate $\mathrm{C}_{60} \cdot 12 \mathrm{C}_{6} \mathrm{H}_{12}$, $\mathrm{C}_{70} \cdot 12 \mathrm{C}_{6} \mathrm{H}_{12}, \mathrm{C}_{60} \cdot 12 \mathrm{CCl}_{4}, \mathrm{C}_{60} \cdot 2 \mathrm{CHBr}_{3}, \mathrm{C}_{60} \cdot 2 \mathrm{CHCl}_{3}, \mathrm{C}_{60} \cdot 2$ $\mathrm{H}_{2} \mathrm{CCl}_{2}$. Anorg. Allg. Chemie, 1995, 621, 14-18.

[94] Barrio, M.; López, D.O.; Tamarit, J.LI.; Szwarc, H.; Toscani, S.; Céolin, R. Chem. Phys. Lett., 1996, 260, 78-81. [95] Barrio, M.; López, D.O.; Tamarit, J.LI.; Espeau, P.; Céolin, R. Solid-state studies of $\mathrm{C}_{60}$ solvates formed in the $\mathrm{C}_{60}-\mathrm{BrCCl}_{3}$ system. Chem. Mater., 2003, 15, 288-291. [96] Macovez, R.; Mitsari, E.; Zachariah, M.; Romanini, M.; Zygouri, P.; Gournis, D.; Tamarit, J. Ll. Ultraslow dynamics of water in organic molecular solids. J. Phys. Chem. C, 2014, 118, 4941-4950.

[97] Dinnebier, R.E.; Stephens, P.W.; Carter, J.K.; Lommen, A.N.; Heiney P.A.; McGhie, A.R.; Brard, L.; Smith III, A.B. $\mathrm{X}$-ray Powder Diffraction Structure of Triclinic $\mathrm{C}_{60} \mathrm{Br}_{24}\left(\mathrm{Br}_{2}\right)_{2}$. J. Appl. Cryst., 1995, 28, 327-334. [98] Kawasaki, S.; Aketa, T.; Touhara, H.; Okino, F.; Boltalina, O. V.; Gol'dt, I. V.; Troyanov, S. I.; Taylor, R. Crystal Structures of the Fluorinated Fullerenes $\mathrm{C}_{60} \mathrm{~F}_{36}$ and $\mathrm{C}_{60} \mathrm{~F}_{48}$. J. Phys. Chem. B, 1999, 103, 1223-1225.

[99] Vaughan, G. B. M.; Chabre, Y.; Dubois, D. Effect of stacking disorder on the orientational ordering transition of solid $\mathrm{C}_{60}$. Europhys. Lett., 1995, 31, 525-530.

[100] Gallagher, S.H.; Armstrong, R.S.; Lay, P.A.; Reed, C.A. Solvent effects on the electronic spectrum of $\mathrm{C}_{60} . J$. Phys. Chem., 1995, 99, 5817-5825.

[101] Allemand P M, Khemani K C, Koch A, Wudl F, Holczer K, Donovan S, Gruner G, Thompson J D. Organic molecular soft ferromagnetism in a fullerene $\mathrm{C}_{60}$. Science, 1991, 253, 301-303.

[102] Blinc, R.; Jeglic, P.; Apih, T.; Seliger, J.; Arcon, D.; Omerzu, A. Beltlike $\mathrm{C}_{60}^{-}$electron spin density distribution in the organic ferromagnet TDAE - $\mathrm{C}_{60}$. Phys. Rev. Lett., 2002, 88, 086402.

[103] Arcon, D.; Blinc, R. The Jahn-Teller effect and fullerene ferromagnets. In: Fullerene-Based Materials: Structures and Properties. Mingos, D.M.P.; Prassides, K., EdsSpringer-Verlag: Berlin, 2004; Structure and Bonding, Vol. 109, pp. 231-276.

[104] Mrzel, A.; Omerzu, A.; Umek, P.; Mihailovic, D.; Jaglicic, Z.; Trontelj, Z. Ferromagnetism in a cobaltocenedoped fullerene derivative below $19 \mathrm{~K}$ due to unpaired spins only on fullerene molecules. Chem. Phys. Lett., 1998, 298, 329-334.

[105] Takenobu, T.; Muro, T.; Iwasa, Y.; Mitani, T. Antiferromagnetism and phase diagram in ammoniated alkali fulleride salts. Phys. Rev. Lett., 2000, 85, 381-384.

[106] Tycko, R.; Dabbagh, G.; Fleming, R.M.; Haddon, R.C.; Makhija, A.V.; Zahurak, S.M. Molecular dynamics and the phase transition in solid $\mathrm{C}_{60}$. Phys. Rev. Lett., 1991, 67, 1886. 
[107] David, W.I.F.; Ibberson, R.M.; Matthewman, J.C.; Prassides, K.; Dennis, T.J.; Hare, J.P.; Kroto, H.W.; Taylor, R.; Walton, D.R.M. Crystal structure and bonding of ordered $\mathrm{C}_{60}$. Nature, 1991, 353, 147-149

[108] Gugenberger, F.; Heid, R.; Meingast, C.; Adelmann, P.; Braun, M.; Wühl, H.; Haluska, M.; Kuzmany, H. Glass transition in single-crystal $\mathrm{C}_{60}$ studied by high-resolution dilatometry. Phys Rev Lett., 1992, 69, 3774.

[109] J.L. de Boer, J.L.; van Smaalen, S.; Petricek, V.; Dusek, M.; Marcel, P.; Verheijen, A.; Meijer, G. Hexagonal close-packed $\mathrm{C}_{60}$. Chem. Phys. Lett., 1994, 219, 469-472 [110] Céolin, R.; Tamarit, J.Ll.; López, D.O.; Barrio, M.; Agafonov, V.; Allouchi, H.; Moussa, F.; Szwarc, H. A new hexagonal phase of fullerene $\mathrm{C}_{60}$. Chem. Phys. Lett., 1999, 314, 21-26.

[111] Park, C.; Song, H.J.; Choi, H.C. The critical effect of solvent geometry on the determination of fullerene $\left(\mathrm{C}_{60}\right)$ self-assembly into dot, wire and disk structures. Chem. Commun., 2009, 32, 4803-4805

[112] Zhang, Y.; Jiang, L.; Li, H., Fan, L.; Hu, W.; Wang, C.; Li, Y.; Yang, S. Single-crystalline $\mathrm{C}_{60}$ nanostructures by sonophysical preparation: tuning hollow nanobowls as catalyst supports for methanol oxidation. Chem. Eur. J., 2011, 17, 4921-4926.

[113] Hawkins, J.M.; Meyer, A.; Lewis, T.A.; Loren, S.; Hollander, F.J.; Crystal structure of osmylated $\mathrm{C}_{60}$ : Confirmation of the soccer ball framework. Science, 1991, 252, 312-313.

[114] Taylor, R.; Walton, R.M. The chemistry of fullerenes. Nature, 1993, 363, 685-693.

[115] Fischer, J.E.; Heiney, P.A. Order and disorder in fullerene and fulleride solids. J. Phys. Chem. Solids, 1993, $54,1725-1757$.

[116] Van Smaalen, S.; Dinnebier, R.; Holleman, I.; von Helden, G.; Meijer, G. Rotational order in CO-intercalated $\mathrm{C}_{60}$ crystals. Phys. Rev. B, 1998, 57, 6321.

[117] Gu, M.; Wang, Y.; Tang, T.B.; Zhang, W.; Hu, C.; Yan, F.; Feng, D. The transition from the ordered to the merohedral disordered phase in oxygenated solid $\mathrm{C}_{60}$. Phys. Lett. A, 1996, 223, 273-279.

[118] Grell, A.-S.; Masin, F.; Ceolin, R.; Gardette, M.-F.; Szwarc, H. Molecular dynamics of $\mathrm{C}_{60} \cdot 2 \mathrm{~S}_{8}: \mathrm{A}^{13} \mathrm{C}$ NMR study. Phys. Rev. B, 2000, 62, 3722.

[119] Talyzin, A.V.; Grell, A.-S.; Masin, F.; Sherman, A.B.; Lemanov, V.V.; Lunkenheimer, P.; Brand, R.; Loidl, A. Molecular dynamics of $\mathrm{C}_{70} \mathrm{~S}_{48}$ : Dielectric function and NMR study. J. Phys. Chem. B, 2001, 105, 1162-1167. [120] Yu , H.; Cho, H.-H.; Cho, C.-H.; Kim, K.-H.; Kim, D.Y.; Kim, B.J.; Oh, J.H. Polarity and air-stability transitions in field-effect transistors based on fullerenes with different solubilizing groups. ACS Appl. Mater. Interfaces, 2013, 5, 4865-4871.

[121] Deng, L.-L.; Xie, S.-L.; Yuan, C.; Liu, R.-F.; Feng, J.; Sun, L.-C.; Lu, X. ; Xie, S.-Y.; Huang, R.-B.; Zheng, L.-S. High LUMO energy level $\mathrm{C}_{60}\left(\mathrm{OCH}_{3}\right)_{4}$ derivatives: electronic acceptors for photovoltaic cells with higher open-circuit voltage. Sol. Energ. Mat. Sol. C., 2013, 111, 193-199.
[122] Li, C.-Z.; Chueh, C.-C.; Yip, H.-L.; Zou, J.; Chen, W.C.; Jen, A.K.-Y. Evaluation of structure-property relationships of solution-processible fullerene acceptors and their n-channel field-effect transistor performance. J. Mater. Chem., 2012, 22, 14976.

[123] Zhang, X.; Li, X.D.; Ma, L.X.; Zhang, B. Electronic and electrochemical properties as well as flowerlike supramolecular assemblies of fulleropyrrolidines bearing ester substituents with different alkyl chain lengths. RSC Adv., 2014, 4, 60342.

[124] Maibach, J.; Adermann, T.; Glaser, T.; Eckstein, R.; Mankel, E.; Pucci, A.; Müllen, K.; Lemmer, U.; Hamburger, M.; Mayer, T.; Jaegermann, W. Impact of processing on the chemical and electronic properties of phenyl- $\mathrm{C}_{61}$-butyric acid methyl ester. J. Mater. Chem. C, 2014, 2, 7934-7942.

[125] Hashiuchi, M.; Obata, N.; Maruyama, M.; Yeo, K.S.; Ueno, T.; Ikebe, T.; Takahashi, I.; Matsuo, Y. $\mathrm{FeCl}_{3}-$ mediated synthesis of fullerenyl esters as low-LUMO acceptors for organic photovoltaic devices. Org. Lett., 2012 , 14, 3276-3279.

[126] Macovez, R.; Savage, R.; Venema, L.; Schiessling, J.; Kamaras, K.; Rudolf, P.; Low band gap and ionic bonding with charge transfer threshold in the polymeric lithium fulleride $\mathrm{Li}_{4} \mathrm{C}_{60}$. J. Chem. Phys. C, 2008, 112, 2988-2996. [127] Samuely, T.; Liu, S.X.; Haas, M.; Decurtins, S.; Jung, T.A.; Stőhr, M. Self-assembly of individually addressable complexes of $\mathrm{C}_{60}$ and phthalocyanines on a metal surface : Structural and electronic investigations. J. Phys. Chem. C, 2009, 113, 19373- 19375.

[128] Macovez, R.; Hunt, M.R.C.; Goldoni, A.; Pedio, M.; Rudolf, P. Surface Hubbard U of alkali fullerides. $J$.

Electron Spectrosc., 2011, 183, 94-100.

[129] Themlin, J.-M.; Bouzidi, S.; Coletti, F.; Debever, J.M.; Gensterblum, G.; Yu, L.-M.; Pireaux, J.-J.; Thiry, P.A. One-dimensional commensurability and conduction-band dispersion in heteroepitaxial $\mathrm{C}_{60}$ on GeS. Phys. Rev. B, 1992, 46, 15602 .

[130] Benning, P.J.; Olson, C.G.; Lynch, D.W. Band dispersion in $\mathrm{C}_{60}(111)$ : An angle-resolved photoemission study. Phys. Rev. B, 1994, 50, 11239.

[131] Gensterblum, G.; Pireaux, J.-J.; Thiry, P. A.; Caudano, R.; Buslaps, T.; Johnson, R.L.; Lay, G.L.; Aristov, V.; Günther, R.; Taleb-Ibrahimi, A.; Indlekofer, G.; Petroff, Y. Experimental evidence for 400-meV valence-band dispersion in solid $\mathrm{C}_{60}$. Phys. Rev. B, 1993, 48, 14756.

[132] Olson, J.R.; Topp, K.A.; Pohl, R.O. Specific heat and thermal conductivity of solid fullerenes. Science, 1993, 259, $1145-1148$.

[133] Duda, J.C.; Hopkins, P.E.; Shen, Y.; Gupta, M.C. Exceptionally low thermal conductivities of films of the fullerene derivative PCBM. Phys. Rev. Lett., 2013, 110, 015902.

[134] Wang, X.; Liman, C.D.; Treat, N.D.; Chabinyc, M.L.; Cahill, D.G. Ultralow thermal conductivity of fullerene derivatives. Phys. Rev. B, 2013, 88, 075310. 
[135] Cahill, D.G.; Watson, S.K.; Pohl, R.O. Lower limit to the thermal conductivity of disordered crystals. Phys. Rev. B, 1992, 46, 6131.

[136] Riccò, M.; Belli, M.; Mazzani, M.; Pontiroli, D.; Quintavalle, D.; Janossy, A.; Csanyi, G. Superionic conductivity in the $\mathrm{Li}_{4} \mathrm{C}_{60}$ fulleride polymer. Phys. Rev. Lett., 2009, 102, 145901.

[137] Li, Y.M.; Hinokuma, K. Proton conductivity of phosphoric acid derivative of fullerene. Solid State Ionics, 2002, 150, 309-315.

[138] Cramer, C.; De, S.; Schönhoff, M. Time-humiditysuperposition principle in electrical conductivity spectra of ion-conducting polymers. Phys. Rev. Lett., 2011, 107, 028301 .

[139] Stankiewicz, J.; Tomás, M.; Dobrinovitch, I.T.; Forcén-Vázquez, E.; Falvello, L.R. Proton conduction in a nonporous one dimensional coordination polymer. Chem. Mater., 2014, 26, 5282-5287.

[140] Macovez, R.; Zachariah, M.; Romanini, M.; Zygouri, P.; Gournis, D.; Tamarit, J.L1. Hopping conductivity and polarization effects in a fullerene derivative salt. J. Phys. Chem. C, 2014, 118, 12170-12175.

[141] van Staveren, M.P.J.; Brom, H.B.; de Jongh, L.J. Metal-Cluster compounds and universal features of the hopping conductivity of solids. Phys. Rep., 1991, 208, 1-96 [142] Shklovskii, B. I.; Efros, A. L. Electronic Properties of Doped Semiconductors; Springer: Berlin, 1984.

[143] Capaccioli, S.; Lucchesi, M.; Rolla, P. A.; Ruggeri, G. Dielectric Response Analysis of a Conducting Polymer Dominated by the Hopping Charge Transport. J. Phys.: Condens. Matter., 1998, 10, 5595-5617 and references therein

[144] Huijbregts, L. J.; Brom, H. B.; Brokken-Zijp, J. C. M.; Kemerink, M.; Chen, Z.; de Goeje, M. P.; Yuan, M.; Michels, M. A. J. The Optimal Structure-Conductivity Relation in Epoxy-Phthalocyanine Nanocomposites. J. Phys. Chem. B, 2006, 110, 23115-23122.

[145] Yu, D.; Wang, C.; Wehrenberg, B.L.; Guyot-Sionnest, P. Variable Range Hopping Conduction in Semiconductor Nanocrystal Solids. Phys. Rev. Lett., 2004, 92, 216802.

[146] Kincs, J.; Martin, S.W. Non-Arrhenius conductivity in glass: mobility and conductivity saturation effects. Phys.

Rev. Lett., 1996, 76, 70.

[147] Sardenberg R. B.; Teixeira, C. E.; Pinheiro, M.; Figueiredo, J.M.A. Nonlinear Conductivity of Fullerenol Aqueous Solutions. ACS Nano, 2011, 5, 2681-2686 [148] Rajagopalan, M.; Oh, I.-K. Fullerenol-based electroactive artificial muscles utilizing biocompatible polyetherimide. ACS Nano, 2011, 5, 2248-2256.

[149] Tasaki, K.; Venkatesan, A.; Wang, H.; Jousselme, B.; Stucky, G.; Wudl, F. Hydrogen cyanofullerene derivatives as acid for proton conducting membranes. J. Electrochem. Soc., 2008, 155, B1077-B1084.

[150] Hinokuma, K.; Ata, M. Fullerene Proton Conductors. Chem. Phys. Lett., 2001, 341, 442-446.

[151] Tripathi, P.; Gonzalo-Ruiz, J.; Mitsari, E.; Zachariah, M.; Romanini, M.; Tamarit, J.L1.; Muñoz, F.; Macovez. R.
Silicon-chip-based dielectric spectroscopy for conductivity and molecular dynamics studies of organic films. J. Phys. Chem. Lett., 2014, 5, 2796-2801.

[152] Sun, Y.-P.; Wang, P.; Hamilton, N.B.; Fluorescence spectra and quantum yields of buckminsterfullerene $\left(\mathrm{C}_{60}\right)$ in room-temperature solutions. No excitation wavelength dependence. J. Am. Chem. Soc., 1993, 115, 6378-6381. [153] Guldi, D.M.; Maggini, M.; Scorrano, G.; Prato, M. Intramolecular electron transfer in fullerene/ferrocene based donor-bridge-acceptor dyads. J. Am. Chem. Soc., 1997, 119, 974-980.

[154] Guldi, D.M.; Asmus, K.-D. Photophysical properties of mono- and multiply-functionalized fullerene derivatives. J. Phys. Chem. A, 1997, 101, 1472-1481.

[155] Armaroli, N.; Accorsi. G. Light-Induced Processed in Fullerene Multicomponent Systems. In: Fullerenes:

Principles and Applications; Langa F.; Nierengarten, J.-F., Eds.; RSC Nanoscience and Nanotechnology - RSC Publishing, Cambridge, UK, 2007.

[156] Loutfy, R.O.; Katagiri, S. Fullerene Materials for Lithium-ion Battery Applications. In: Perspectives of Fullerene Nanotechnology; Osawa, E., Ed.; Kluwer Academic Publishers, Dordrecht, The Netherlands 2002; pp. 357-367.

[157] Koudoumas, E.; Konstantaki, M.; Mavromanolakis, A.; Couris, S.; Fanti, M.; Zerbetto, F.; Kordatos, K.; Prato, M. Large enhancement of the nonlinear optical response of reduced fullerene derivatives. Chem. Eur. J., 2003, 9, 15291534.

[158] Ouyang, X.; Zeng, H.; Ji, W. Synthesis, strong twophoton absorption, and optical limiting properties of novel $\mathrm{C}_{70} / \mathrm{C}_{60}$ derivatives containing various carbazole units. $J$. Phys. Chem. B, 2009, 113, 14565- 14573.

[159] Waldauf, C.; Schilinsky, P.; Perisutti, M.; Hauch, J.; Brabec, C.J. Solution-processed organic n-type thin-film transistors. Adv. Mater., 2003, 15, 2084-2088.

[160] Chikamatsu, M.; Itakura, A.; Yoshida, Y.; Azumi, R.; Yase, K. High-performance n-type organic thin-film transistors based on solution-processable perfluoroalkylsubstituted $\mathrm{C}_{60}$ derivatives. Chem. Mater., 2008, 20, 7365 7367.

[161] Wobkenberg, P.H.; Ball, J.; Bradley, D.D.C.; Anthopoulos, T.D.; Kooistra, F.; Hummelen, J.C.; de Leeuw, D.M. Fluorine containing $\mathrm{C}_{60}$ derivatives for highperformance electron transporting field-effect transistors and integrated circuits. Appl. Phys. Lett., 2008, 92, 143310. [162] Tiwari, S.P.; Zhang, X.-H.; Potscavage, W.J.; Kippelen, Jr.B. Study of electrical performance and stability of solution-processed n-channel organic field-effect transistors. J. Appl. Phys., 2009, 106, 054504.

[163] Yu, G.; Gao, J.; Hummelen, J.C.; Wudl, F.; Heeger, A.J. Polymer photovoltaic cells : Enhanced efficiencies via a network of internal donor-acceptor heterojunctions. Science, 1995, 270, 1789-1791.

[164] Marjanovic, N.; Singh, Th.B.; Dennler, G.; Günes, S.; Neugebauer, H.; Sariciftci, N.S.; Schwodiauer, R.; Bauer, S. Photoresponse of organic field-effect transistors based on 
conjugated polymer/fullerene blends. Org. Electron., 2006, 7, 188-194.

[165] Thompson, B.C.; Frechet, J.M.J. Polymer-fullerene composite solar cells. Angew. Chem. Int. Ed., 2008, 47, 5877.

[166] Blom, P.W.M.; Mihailetchi, V.D.; Koster, L.J.A.; Markov, D.E. Device physics of polymer: Fullerene bulk heterojunction solar cells. Adv. Mater., 2007, 19, 1551-1566. [167] Troshin, P.A.; Hoppe, H.; Renz, J.; Egginer, M.; Mayorova, J.Y.; Goryachev, A.E.; Peregudov, A.S.; Lyubovskaya, R.N.; Gobsch, G.; Sariciftci, N.S.; Razumov, V.F. Material solubility-photovoltaic performance relationship in the design of novel fullerene derivatives for bulk heterojunction solar cells. Adv. Funct. Mater., 2009, 19, $779-788$.

[168] de Leeuw, D.M.; Simenon, M.M.J.; Brown, A.R.; Einerhand, R.E.F. Stability of n-type doped conducting polymers and consequences for polymeric microelectronic devices. Synth. Met., 1997, 87, 53-59.

[169] Jones, B.A.; Facchetti, A.; Wasielewski, M.R.; Marks, T.J. Tuning orbital energetics in arylene diimide semiconductors. Materials design for ambient stability of ntype charge transport. J. Am. Chem. Soc., 2007, 129, 1525915278.

[170] Anthopoulos, T.D.; Anyfantis, G.C.; Papavassiliou, G.C.; de Leeuw, D.M. Air-stable ambipolar organic transistors. Appl. Phys. Lett., 2007, 90, 122105.

[171] Usta, H.; Risko, C.; Wang, Z.; Huang, H.;

Deliomeroglu, M.K.; Zhukovitskiy, A.; Facchetti, A.; Marks, T.J. Design, synthesis, and characterization of ladder-type molecules and polymers. air-stable, solution-processable nchannel and ambipolar semiconductors for thin-film transistors via experiment and theory. J. Am. Chem. Soc., 2009, 131, 5586-5608.

[172] Weitz, R.T.; Amsharov, K.; Zschieschang, U.; Burghard, M.; Jansen, M.; Kelsch, M.; Rhamati, B.; van Aken, P.A.; Kern, K.; Klauk, H. The importance of grain boundaries for the time-dependent mobility degradation in organic thin-film transistors. Chem. Mater., 2009, 21, 49494954.

[173] Anthopoulos, T.D.; Singh, B.; Marjanovic, N.; Sariciftci, N.S.; Ramil, A.M.; Sitter, H.; Cölle, M.; de Leeuw, D.M. High performance n-channel organic fieldeffect transistors and ring oscillators based on $\mathrm{C}_{60}$ fullerene films. Appl. Phys. Lett., 2006, 89, 213504.

[174] Haddon, R.C. C 70 thin film transistors. J. Am. Chem. Soc., 1996, 118, 3041-3042.

[175] Zhang, X.-H.; Domercq, B.; Kippelen, B. Highperformance and electrically stable $\mathrm{C}_{60}$ organic field-effect transistors. Appl. Phys. Lett., 2007, 91, 092114.

[176] Wöbkenberg, P.H.; Bradley, D.D.C.; Kronholm, D.; Hummelen, J.C.; de Leeuw, D.M.; Cölle, M.; Anthopoulos, T.D. High mobility n-channel organic field-effect transistors based on soluble $\mathrm{C}_{60}$ and $\mathrm{C}_{70}$ fullerene derivatives. Synth. Met., 2008, 158, 468-472.

[177] Singh, Th.B.; Marjanović, N.; Stadler, P.; Auinger, M.; Matt, G.J.; Günes, S.; Sariciftci, N.S.; Schwödiauer, R.;
Bauer, S. Fabrication and characterization of solutionprocessed methanofullerene-based organic field-effect transistors. J. Appl. Phys., 2005, 97, 083714.

[178] Anthopoulos, T.D. ; Tanase, C.; Setayesh, S.; Meijer, E. J.; Hummelen, J.C.; Blom, P.W.M.; de Leeuw, D.M. Ambipolar organic field-effect transistors based on a solution-processed methanofullerene. Adv. Mater., 2004, 16, 2174-2179.

[179] Anthopoulos, T.D.; de Leeuw, D.M.; Cantatore, E.; van't Hof, P.; Alma, J.; Hummelen, J.C. Solution processable organic transistors and circuits based on a $\mathrm{C}_{70}$ methanofullerene. J. Appl. Phys., 2005, 98, 054503.

[180] Cravino, A.; Sariciftci. N. Double-cable polymers for fullerene based organic optoelectronic applications. J. Mater. Chem., 2002, 12, 1931-1943.

[181] He, D.; Du, X.; Xiao, Z.; Ding, L. Methanofullerenes, $\mathrm{C}_{60}\left(\mathrm{CH}_{2}\right)_{n}(n=1,2,3)$, as building blocks for

high-performance acceptors used in organic solar cells. Org. Lett., 2014, 16, 612-615.

[182] Roncali, J. Single material solar cells: The next frontier for organic photovoltaics? Adv. Energy Mater., 2011, 1, 147-160.

[183] Salice, P.; Ronchi, E.; Iacchetti, A.; Binda, M.; Natali, D.; Gomulya, W.; Manca, M.; Loi, M.A.; Iurlo, M.; Paolucci, F.; Maggini, M.; Pagani, G.A.; Beverina, L.; Menna, E. A fulleropyrrolidine-squaraine blue dyad: Synthesis and application as an organic light detector. $J$. Mater. Chem. C, 2014, 2, 1396-1399.

[184] Koeppe, R.; Sariciftci, N.S. Photoinduced charge and energy transfer involving fullerene derivatives. Photochem. Photobiol. Sci., 2006, 5, 1122-1131

[185] Ito, O.; D’Souza. F. Recent advances in photoinduced electron transfer processes of fullerene-based molecular assemblies and nanocomposites. Molecules, 2012, 17, 58165835.

[186] Martín, N.; Sanchez, L.; Herranz, M.A.; Illescas, B.; Guldi, D.M. Electronic communication in tetrathiafulvalene (TTF)/ $\mathrm{C}_{60}$ systems: toward molecular solar energy conversion materials? Acc. Chem. Res., 2007, 40, 1015-1024.

[187] Fukuzumi, S.; Kojima, T. Photofunctional nanomaterials composed of multiporphyrins and carbonbased $\pi$-electron acceptors. J. Mater. Chem., 2008, 18, 1427-1439.

[188] Bottari, G.; de la Torre, G.; Guldi, D.M.; Torres, T. Covalent and noncovalent phthalocyanine-carbon nanostructure systems: synthesis, photoinduced electron transfer, and application to molecular photovoltaics. Chem. Rev., 2010, 110, 6768-6816.

[189] D'Souza, F.; Ito, O. Photosensitized electron transfer processes of nanocarbons applicable to solar cells. Chem. Soc. Rev., 2012, 41, 86-96.

[190] Umeyama T.; Imahori, H. Photofunctional hybrid nanocarbon materials. J. Phys. Chem. C, 2013, 117, 3195-3209. 
[191] Gust, D.; Moore, T.A.; Moore, A.L. Mimicking photosynthetic solar energy transduction, Acc. Chem. Res., 2001, 34, 40-48.

[192] Imahori, H.; Sakata, Y. Donor-linked fullerenes: Photoinduced electron transfer and its potential application. Adv. Mater., 1997, 9, 537-546.

[193] Imahori, H.; Sakata, Y. Fullerenes as novel acceptors in photosynthetic electron transfer. Eur. J. Org. Chem., 1999, 1999, 2445-2457.

[194] Kodis, G.; Terazono, Y.; Liddell, P.A.; Andréasson, J.; Garg, V.; Hambourger, M.; Moore, T.A.; Moore, A.L.; Gust, D. Energy and photoinduced electron transfer in a wheelshaped artificial photosynthetic antenna-reaction center complex. J. Am. Chem. Soc., 2006, 128, 1818-1827. [195] Kuciauskas, D.; Liddell, P.A.; Lin, S.; Johnson, T.E.; Weghorn, S.J.; Lindsey, J.S.; Moore, A.L.; Moore, T.A.; Gust, D. An artificial photosynthetic antenna-reaction center complex. J. Am. Chem. Soc., 1999, 121, 8604-8614.

[196] Imahori, H. Porphyrin-fullerene linked systems as artificial photosynthetic mimics. Org. Biomol. Chem., 2004, 2, 1425-1433.

[197] Sariciftci, N.S; Smilowitz, L; Heeger, A.J.; Wudl, F. Photoinduced electron transfer from a conducting polymer to Buckminsterfullerene. Science, 1992, 258, 1474-1476. [198] Wang, T.; Pearson, A.J.; Lidzey, D.G. Correlating molecular morphology with optoelectronic function in solar cells based on low band-gap copolymer: fullerene blends. $J$. Mater. Chem. C, 2013, 1, 7266-7293.

[199] He, Y.; Chen, H.Y.; Hou, J.; Li, Y. Indene-C 60 bisadduct: a new acceptor for high-performance polymer solar cells. J. Am. Chem. Soc., 2010, 132, 13771382.

[200] Wong, W.W.H.; Subbiah, J.; White, J.M.; Seyler, H.; Zhang, B.; Jones, D.J.; Holmes, A.B. Single isomer of indene- $\mathrm{C}_{70}$ bisadduct - Isolation and performance in bulk heterojunction solar cells. Chem. Mater., 2014, 26, 1686-1689.

[201] Ye, G.; Chen, S.; Xiao, Z.; Zuo, Q.; Wei, Q.; Ding, L. o-Quinodimethane-methano[60]fullerene and thieno-oquinodimethanemethano[60]fullerene as efficient acceptor materials for polymer solar cells. J. Mater. Chem., 2012, 22, 22374

[202] He, Z.; Zhong, C.; Su, S.; Xu, M.; Wu, H.; Cao Y. Enhanced power-conversion efficiency in polymer solar cells using an inverted device structure. Nat. Photonics, 2012, 6, 591-595.

[203] Lai, Y.-Y.; Cheng, Y.-J.; Hsu, C.-S. Applications of functional fullerene materials in polymer solar cells. Energy Environ. Sci., 2014, 7, 1866-1883.

[204] Xiao, Z.; He, D.; Zuo, C.; Gan, L.; Ding, L. An azafullerene acceptor for organic solar cells. RSC Adv., 2014, 4, 24029-24031.

[205] Zhang, C.; Chen, S.; Xiao, Z.; Zuo, Q.; Ding, L.

Synthesis of mono- and bisadducts of thieno-oquinodimethane with $\mathrm{C}_{60}$ for efficient polymer solar cells. Org. Lett., 2012, 14, 1508-1511.
[206] Chen, S.; Ye, G.; Xiao, Z.; Ding, L. Efficient and thermally stable polymer solar cells based on a $54 \pi$-electron fullerene acceptor. J. Mater. Chem. A, 2013, 1,5562-5566 [207] Lu, S.; Jin, T.; Yasuda, T.; Si, W.; Oniwa, K.; Alamry, K.A.; Kosa, S.A.; Asiri, A.M.; Han, L.; Yamamoto, Y. Deuterium isotope effect on bulk heterojunction solar cells. Enhancement of organic photovoltaic performances using monobenzyl substituted deuteriofullerene acceptors. Org. Lett., 2013, 15, 5674-5677.

[208] He, D.; Zuo, C.; Chen, S.; Xiao, Z.; Ding, L. A highly efficient fullerene acceptor for polymer solar cells. Phys. Chem. Chem. Phys., 2014, 16, 7205-7208.

[209] Wong, W.W.H.; Vak, D.; Singh, T.B.; Ren, S.; Yan, C.; Jones, D.J.; Liaw, I.I.; Lamb, R.N.; Holmes, A.B. Ambipolar hexa-peri-hexabenzocoronene-fullerene hybrid materials. Org. Lett., 2010, 12, 5000-5003.

[210] Troshin, P.; Hoppe, H.; Renz, J.; Egginger, M.; Mayorova, J.Y.; Goryachev, A.E.; Peregudov, A. S.; Lyubovskaya, R. N.; Gobsch, G.; Sariciftci, N. S.; Razumov, V.F. Material solubility-photovoltaic performance relationship in the design of novel fullerene derivatives for bulk heterojunction solar cells. Adv. Funct. Mater., 2009, 19, 779-788.

[211] Sahu S.; Pal, A.J. Donor/acceptor type photodetectors: Role of substitution in acceptor material. J. Appl. Phys., 2006, 99, 114503.

[212] Vinodgopal, K.; Haria, M.; Meisel, D.; Kamat, P. Fullerene-based carbon nanostructures for methanol oxidation. Nano Lett., 2004, 4, 415-418.

[213] Tzirakis, M.D.; Vakros, J.; Loukatzikou, L.; Amargianitakis, V.; Orfanopoulos, M.; Kordulis, C.; Lycourghiotis, A. $\gamma$-Alumina-supported [60] fullerene catalysts: Synthesis, properties and applications in the photooxidation of alkenes. J. Mol. Catal. A: Chem., 2010, 316, 65-74.

[214] Lin, J.; Zong, R.; Zhou, M.; Zhu, Y. Photoelectric catalytic degradation of methylene blue by $\mathrm{C}_{60}$-modified $\mathrm{TiO}_{2}$ nanotube array. Appl. Catal. B: Environ., 2009, 89, 425-431.

[215] Niu, F.; Wu, J.; Zhang, L.; Li, P.; Zhu, J.; Wu, Z.; Wang, C.; Song, W. Hydroxyl group rich $\mathrm{C}_{60}$ fullerenol: An excellent hydrogen bond catalyst with superb activity, selectivity, and stability. ACS Catal., 2011, 1, 1158-1161. [216] Zhuo, J.; Wang, T.; Zhang, G.; Liu, L.; Gan, L.; Li, M. Salts of $\mathrm{C}_{60}(\mathrm{OH})_{8}$ electrodeposited onto a glassy carbon electrode: Surprising catalytic performance in the hydrogen evolution reaction. Angew. Chem. Int. Ed., 2013, 52, $10867-$ 10870 .

[217] Gao, F.; Zhao G.-L., Yang, S.; Spivey, J.J. Nitrogendoped fullerene as a potential catalyst for hydrogen fuel cells. J. Am. Chem. Soc., 2012, 135, 3315-3318.

[218] Tada, T.; Kanayama, T. Nanolithography using fullerene films as an electron beam resist. Jpn. J. Appl. Phys., 1996, 35, L63.

[219] Tada, T.; Uekusa, K.; Kanayama, T.; Nakayama, T.; Chapman, R.; Cheung, W.; Y. Eden, L.; Hussain, I.; Jennings, M.; Perkins, J.; Phillips, M.; Preecec, J. A. 
Shelley, E. Multi-adduct derivatives of $\mathrm{C}_{60}$ for electron beam nano-resists. Microelectron. Eng., 2002, 61-62, 737-743. [220] Okamura, H.; Forman, D.C.; Ober, C.K. $\mathrm{C}_{60^{-}}$ containing polymers for electron beam lithography. Polym. Bull., 2014, 71, 2395-2405.

[221] Gibbons, F.; Zaid, H.M.; Manickam, M.; Preece, J.A.; Palmer, R.E.; Robinson, A.P.G. A chemically amplified fullerene-derivative molecular electron-beam resist. Small, 2007, 3, 2076-2080.

[222] Yang, D.X.; Frommhold, A;. Xue, X.; Palmer, R.E.; Robinson, A.P.G. Chemically amplified phenolic fullerene electron beam resist. J. Mater. Chem. C, 2014, 2, 15051512.

[223] Kaskhedikar, N. A.; Maier, J. Lithium storage in carbon nanostructures. Adv. Mater., 2009, 21, 2664-2680. [224] Seger, L.; Wen, L.-Q.; Schlenoff, J.B. Prospects for using $\mathrm{C}_{60}$ and $\mathrm{C}_{70}$ in lithium batteries. J. Electrochem. Soc., 1991, 138, L81-L82.

[225] Cristofolini, L.; Riccò, M.; De Renzi, R. NMR and high-resolution $\mathrm{x}$-ray diffraction evidence for an alkali-metal fulleride with large interstitial clusters: $\mathrm{Li}_{12} \mathrm{C}_{60}$. Phys. Rev. $B$, 1999, 59, 8343.

[226] Hamamoto, N.; Jitsukawa, J.; Sakoto, C. Electronic and geometric properties of alkali- $\mathrm{C}_{60}$ molecules. Eur. Phys. J. D, 2002, 19, 211-221.

[227] Wang, F.F.; Wang, C.; Liu, R.Q.; Tian, D.; Li, N. Experimental study on the preparation of Ag nanoparticle doped fullerenol for lithium ion battery application. J. Phys. Chem. C, 2012, 116, 10461-10467.

[228] Brühwiler, P.A.; Andersson, S.; Dippel, M.; M»rtensson, N.; Demirev, P.A.; Sundqvist, Bo U.R. Hydrogenation of solid $\mathrm{C}_{60}$ by atomic hydrogen. Chem. Phys. Lett., 1993, 214, 45-49

[229] Haufler, R.E.; Conceicao, J.; Chibante, L.P.F.; Chai, Y.; Byrne, N.E.; Flanagan, S.; Haley, M.M.; O'Brien, S.C.; Pan, C. Efficient production of $\mathrm{C}_{60}$ (buckminsterfullerene), $\mathrm{C}_{60} \mathrm{H}_{36}$, and the solvated buckide ion. J. Phys. Chem., 1990, 94, 8634-8636.

[230] Guarr, T.F.; Meier, M.S.; Vance, V.K.; Clayton, M. Electrochemistry of the $\mathrm{C}_{60} \mathrm{H}_{2}$ fullerene. J. Am. Chem. Soc., 1993, 115, 9862-9863.

[231] Ruchardt, C.; Gerst, M.; Ebenhoch, J.; Beckhaus, H.; Campbell, E. E. B.; Tellgmann, R.; Schwarz, H.; Weiske, T.; Pitter, S. Transfer hydrogenation and deuteration of buckminsterfullerene $\mathrm{C}_{60}$ by 9,10 -dihydroanthracene and $9,9^{\prime}, 10,10^{\prime}\left[\mathrm{D}_{4}\right]$ dihydroanthracene. Angew. Chem. Int. Ed., 1993, 32, 584-586.

[232] Jin, C.; Hettich, R.; Compton, R.; Joyce, D.; Blenco, J.; Burch, T. Direct Solid-phase hydrogenation of fullerenes. J. Phys. Chem., 1994, 98, 4215-4217.

[233] Brosha, E. L.; Davey, J.; Garzon, F. H.; Gottesfeld, S. Irreversible hydrogenation of solid $\mathrm{C}_{60}$ with and without catalytic metals. J. Mater. Res., 1999, 14, 2138-2146. [234] Talyzin, A.V.; Tsybin, Y.O.; Purcell, J.M.; Schaub, T.M.; Shulga, Y.M.; Noreus, D.; Sato, T.; Dzwilewski, A.; Sundqvist, B.; Marshall, A.G. Reaction of hydrogen gas with $\mathrm{C}_{60}$ at elevated pressure and temperature: hydrogenation and cage fragmentation. J. Phys. Chem. A, 2006, 110, 8528-8534.

[235] Luzan, S.M.; Tsybin, Y.O.; Talyzin, A.V. Reaction of $\mathrm{C}_{60}$ with hydrogen gas: in situ monitoring and pathways. $J$. Phys. Chem. C, 2011, 115, 11484-11492.

[236] Osaki, T.; Tanakab, T.; Taia, Y. Hydrogenation of $\mathrm{C}_{60}$ on alumina-supported nickel and thermal properties of $\mathrm{C}_{60} \mathrm{H}_{36}$. Phys. Chem. Chem. Phys., 1999, 1, 2361-2366. [237] Wang, N.-X.; Wang, L.; Liu, W.; Ou, Y.; Li, W. Some thermal decomposition reactions of $\mathrm{C}_{60} \mathrm{H}_{36}$. Tetrahedron Lett., 2001, 42, 7911-7913.

[238] Wang, N.-X; Zhang, J.-P. Preparation and decomposition of $\mathrm{C}_{60} \mathrm{H}_{36}$. J. Phys. Chem. A, 2006, 110, 6276-6278.

[239] Teprovich Jr., J.A.; Wellons, M.S.; Lascola, R.; Hwang, S.-J.; Ward, P. A.; Compton, R.N.; Zidan, R. Synthesis and characterization of a lithium-doped fullerane $\left(\mathrm{Li}_{\mathrm{x}}-\mathrm{C}_{60}-\mathrm{H}_{\mathrm{y}}\right)$ for reversible hydrogen storage. Nano Lett., 2012, 12, 582-589. 